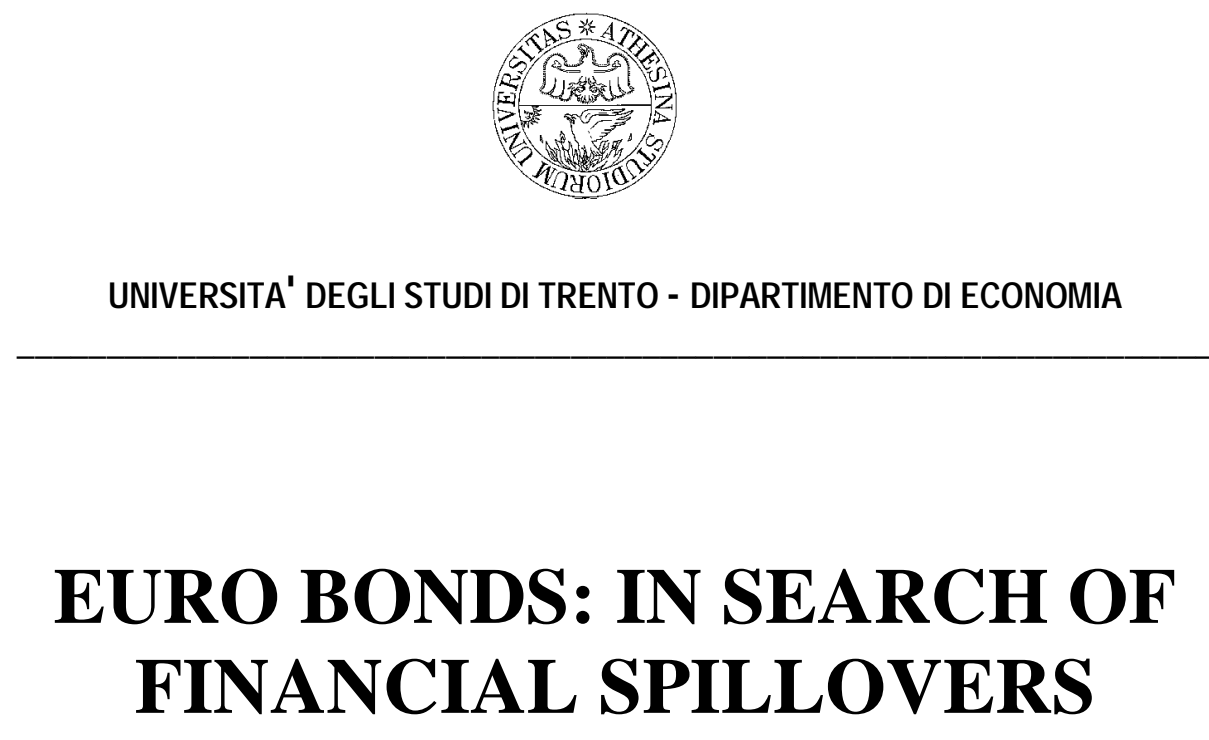

Stefano Schiavo

Discussion Paper No. 2, 2005 
The Discussion Paper series provides a means for circulating preliminary research results by staff of or visitors to the Department. Its purpose is to stimulate discussion prior to the publication of papers.

Requests for copies of Discussion Papers and address changes should be sent to:

Dott. Stefano Comino

Dipartimento di Economia

Università degli Studi

Via Inama 5

38100 TRENTO ITALY 


\title{
Euro Bonds: in Search of Financial Spillovers
}

\author{
Stefano Schiavo* \\ Sant'Anna School of Advanced Studies \\ and University of Trento \\ schiavo@sssup.it
}

January 2005

\begin{abstract}
The paper investigates the empirical relevance of the negative financial spillovers hypothesis according to which fiscal imbalances in one EMU member country bid up the interest rate faced by all other participants in the currency union. This idea questions the ability of financial markets to correctly price various types of risk now that the elimination of exchange rate fluctuations and the rapid integration of national government bond markets have made securities issued by different European governments closer substitutes. The paper takes an eclectic approach and tackles the issue from different angles, reviewing historical episodes, testing the Ricardian equivalence hypothesis in Europe as a whole and finally analyzing the impact of domestic and foreign fiscal variables on European bond yields. Despite the strong comovements displayed by European interest rates, empirical evidence does not support the idea that fiscal variables are a key determinant of these interrelations.
\end{abstract}

\section{Introduction}

The paper investigates the empirical relevance of negative financial spillovers among EMU member countries. The integration of national government bond markets that resulted from the inception of the euro and the consequent elimination of exchange rate risk has rendered securities issued by different EMU governments closer substitute. In a recent survey on financial integration in the euro area Baele, Ferrando,

*I am grateful to Roberto Tamborini, Axel Leijonhufvud, Gabriella Berloffa, Christopher Gilbert, Giuliana Passamani, seminar participants at Università di Trento and at the workshop Lectures on Macroeconomic Governance in the EMU for helpful comments; Flavio Bazzana, Giorgio Cipriani, Gabriella Mazzalai and Enrico Salvetta helped me with the data. Most unfortunately, none of them can be blamed for any remaining mistake. 
Hördahl, Krylova, and Monnet (2004) show that in the last few years movements in government bond yields are increasingly explained by the behavior of the benchmark bond. Out of finance jargon, one can interpret this as evidence of the fact that security returns are now driven more by international factors and less by purely domestic news. Building on this notion, the financial spillovers hypothesis questions the ability of financial markets to correctly price risk and to discriminate among different issuers. More in detail, this hypothesis postulates a link between the fiscal imbalances run by each government in the euro zone and the borrowing costs faced by all other countries participating in the currency area. Such an externality would in turn entail a redistribution of costs through the common monetary policy and result in crowding out of productive investments in economic systems where the interest rate would otherwise be lower. The negative financial spillover hypothesis is often regarded as one of the (few) theoretical foundations of the Stability and Growth Pact (SGP): yet, as it will become apparent below, economic theory does not establish a clear cut link between fiscal variables and the rate of interest. Moreover, despite the fact that the issue remains an empirical question, the hypothesis have been tested explicitly so far.

Beside the relevance for European economic policy - the recent debate about the opportunity and the costs of having binding fiscal rules witnesses for thatthe topic is also interesting on purely academic ground as it rests on two broader unresolved issues in modern macroeconomics: the impact of the fiscal stance on interest rates and whether the latter are determined by stock or by flow variables.

The paper is organized as follows: section 2 contextualizes the financial spillover hypothesis in the recent debate over fiscal rules and the SGP. Section 3 shows that economic theory offers little guidance as not only different models present different implications, but the same model may lead to opposite conclusions when a single assumption is modified. The paper then takes a step backward and section 4 analyzes two episodes in recent past where spillovers from fiscal variables to bond yields may have occurred, namely German unification and the Italian fiscal crisis of the early 1990s. Moving to more formal empirical analysis, section 5 investigates the impact of a European wide fiscal indicator on the average yield on government bonds, section 6 while narrows the focus on a subset of EMU member countries and estimates the effect of fiscal variables on domestic and foreign interest rates. Section 7 concludes.

\section{Negative financial spillovers and the SGP}

Recently the debate about the SGP has regained the center of the stage as late developments of European policy-making, spurred by the current poor economic performance of EMU member countries, questioned (again) the rationale of having binding fiscal rules and opened the door to a more flexible implementation of the provisions of the pact.

The whole process of European integration is based not only on the belief that fiscal discipline is necessary for the correct functioning of a monetary union, but also on the conviction that such discipline must be imposed onto member states 
from above (i.e. from European institutions). By joining a monetary union, in fact, countries are thought to incur in a bias toward excessive deficit since the common monetary policy - tailored to serve the 'representative country' - redistributes costs onto all economies, thus generating an incentive to free-ride (Afonso and Strauch 2004, p. 6). Moreover, easier access to international markets (granted by the EMU) reduces the financial constraint on national governments and thus spurs fiscal laxity. Three sets of mechanisms have been devised to limit this perverse outcome: one aiming at furnishing the ECB with the highest degree of independence and credibility, the second limiting the ability of governments to run fiscal deficits, the third explicitly stating that no co-responsibility exists among member states with respect to national debts (no-bail-out clause). Unfortunately, the emphasis on fiscal restraint that has been characterizing European institutions appears nowadays to damage the support for the European project. To gain some insight, assess the relevance of the hypotheses formulated to support and rationalize the Pact and weight pros and cons of such an institutional framework, it is useful to analyze the reasons that lead to the creation of the SGP.

In the road toward the single currency, at the beginning of the 1990s, European partner countries decided to give themselves a set of condition to fulfill before joining the monetary union. This was done in order to make the monetary reform as smooth at possible. As is well known, the famous criteria required countries willing to join the European Monetary Union (EMU) to achieve a certain degree of convergence in terms of inflation and interest rates; moreover, candidate countries were committed to adopt measures of fiscal consolidation apt to assure low budget deficits and decreasing debt burdens. On the basis of the criteria stated by the Maastricht Treaty, in May 1998 the European Council admitted 11 countries to join the EMU.

The rationale behind these rules was to give a solid fiscal backing to the newly established single currency, limit pressures to monetize fiscal imbalances onto the European Central Bank (ECB), and give the latter a jump start in terms of antiinflationary credibility. The Maastricht Treaty, however, only served to judge potential entrants at one moment in time while having no power to restrain future fiscal stances. Arguably, once admitted a government could start again cumulating fiscal deficits, piling up public debt and so on an so forth. This prospect soon started to spoil the sleep of many European policymakers, especially those facing not-tooEuro-enthusiastic public opinions who feared to incur in a deadweight loss by leaving their good, old, stable national currencies and joining an Euroclub populated also by some monetary scoundrels.

The subsequent debate generated the SGP, which basically gives a permanent status to the fiscal rules contained in the Maastricht Treaty. This agreement (which in truth looks much more concerned with stability than with growth), establishes an institutional framework whereby member countries are required to achieve balanced or surplus budgets on average over the business cycle, while imposing an upper limit to deficits (no larger than 3\% of GDP) in bad years. This cieling to the deficit/GDP ratio is not binding in the (rather unlikely) event of a downturn in real GDP larger than $2 \%$. 
All the criticisms of the SGP directly or indirectly question its foundations and the reasons that lead to its creation. Many of the contributions to the debate, however, fail to distinguish between to separate issues: the need for a pact and the rationale behind this pact.

In one of the contributions contained in the famous Delors Report (Lamfalussy 1989) the author suggests that default in one country may force other members to intervene since part of the defaulted debt would be held by their citizens. However, even when no default occurs, in a deeply integrated market negative financial spillovers can take place. In this case crowding out of more useful/profitable investments would result in countries where the interest rate would otherwise be lower. The basic question is then whether markets are able to discriminate among different issuers. Evidence from US states and Canadian provinces suggests this is indeed the case (see, among others, Bayoumi, Goldstein, and Woglom (1993) and Cheung $(1996))^{1}$. On the other hand Thygesen (1999) reports that in the mid 1990s the premium paid by Italian 10 years government bonds over German Bunds narrowed to 30 basis points ahead of debt reduction.

Restoy (1996) claims that three conditions have to hold for markets to be efficient in pricing risk: (i) free capital mobility, (ii) availability of complete and up-to-date information about member countries' public finance, (iii) credibility of the no-bailout clause. Bayoumi, Goldstein, and Woglom (1993) add a fourth condition, i.e. (iv) resiliency of the financial system to potential failure of a large borrower.

Tamborini (2002) correctly points out that for fiscal rules to be sensible, one needs to assume fiscal stimuli to be expansionary in the home country and contractionary abroad. Otherwise there is no incentive neither to run a budget deficit nor to limit this ability. In his paper, there exist two separate channels through which public spending in one country spills over. A trade channel linking domestic to foreign aggregate demand and production, and a financial channel working via the impact of budget deficits on the common interest and exchange rate. The strength of this latter channel depends crucially on the elasticity of aggregate demand to changes in the interest rate and on money/bond substitutability, i.e. the elasticity of money demand to changes in the interest rate. When the latter is low, a larger movement in the interest rate is required to accommodate the excess demand of money generated by increased production (in turn due to the fiscal expansion). Deeper financial markets integration spurred by the introduction of the single currency should favor money/bond substitutability and hence reduce the strength of this financial channel.

Artis and Winkler (1999) as well identify three ways through which an increase in the interest rate can affect the real economy: crowding out of private investments, appreciation of the exchange rate and consequent decrease of exports, contagion in presence of a crisis. Buiter, Corsetti, and Roubini (1993) elaborate on this contagion effect suggesting that to avoid a credit crunch the ECB would need to inject liquidity into the system, thus raising inflation expectations. This in turn would severely damage the goal of price stability. From an empirical point of view, this kind of

\footnotetext{
${ }^{1}$ The experience of New York State default in 1975 may have made American financial markets efficient in controlling public borrowers.
} 
spillovers working through money demand and the common monetary policy of the ECB should have an impact mainly on short-term rates, i.e. on monetary policy instruments.

Kenen (1995) stresses an absorption effect that is more relevant to our work: by issuing more debt, each country runs the risk of saturating the market by absorbing a large share of European savings ${ }^{2}$. Such demand/supply imbalances would result in a lower price (higher interest rate) for bonds. Again, this channel rests on the assumption that markets do not fully discriminate among different issuers, i.e. that a monetary union makes bonds of different countries (almost) perfect substitutes. If this is not the case, this supply effect would be limited by the fact that securities issued by different countries span different segments of the bond market; increased supply of one bond, then, would only rise the interest rate paid in that particular segment, with low or no repercussions on other 'goods'. For this 'loanable funds' hypothesis to work we need an additional condition to hold, namely that after the introduction of a single currency (and the subsequent elimination of exchange rate risk) European financial markets are closely integrated so that different issuers draw on a single pool of savings. At this point it is worth noting that according to Hartman, Maddaloni, and Manganelli (2003) quantity based indicators show that a significant home bias still remains in European portfolios. The resulting segmentation in asset markets makes Kenen's hypothesis about financial spillovers less likely.

Fiscal events in one country should affect bond yields at the maturity for which the new issue has occurred. Hence, if Italian deficit is financed by means of 10 years bonds, yields on long-term bonds for all other countries should go up. If fiscal imbalances are covered by a mixture of debt instruments spanning the entire maturity spectrum, then the entire yield curve should shift upwards.

The present discussion has placed the issue of negative financial spillovers within the broader frame of the SGP and has shown that it represents one of the main justifications for having binding fiscal rules. In the next section we will go beyond this policy-oriented approach with the aim of investigating whether economic theory offers any support to the idea that a loose fiscal stance in one country may push upward the world rate of interest.

\section{The theoretical background}

The debate about the existence and the relevance of negative financial spillovers rests on two broader theoretical issues in modern macroeconomics: whether fiscal policy has any impact on interest rates and whether the latter are determined by stock or flow variables. This section presents an overview of selected contributions that - far from constituting a comprehensive review of the endless literature on the aforementioned topics - serves the purpose of providing us with a theoretical framework for subsequent analysis and with a context for our discussion.

\footnotetext{
${ }^{2}$ In practice only large enough countries are likely to produce this result.
} 
All models presented here (with the exeption of Branson (1988)) assume solvency is not at stake: therefore changes in bond yields do not affect debt sustainability. The reason for so doing is multifaced: first of all, default should be taken care of by the no-bail-out clause and has in principle little to do with the SGP. On a more practical ground, given current credit ratings the likelihood of default is extremely limited for all EMU member countries ${ }^{3}$. Therefore we will not cover the part of the literature that deals with debt repudiation and default and focus our attention on negative financial spillovers in their narrow meaning, i.e. public spending resulting in crowding out of private expenditure via its effect on the common interest rate.

Yet, addressing the effects of fiscal policy and public deficits postulating the existence of intertemporal equilibrium (as most of the standard models do) is somehow odd and introduces the issue of stability. Although this concept lies at the very core of many macroeconomic models, it is most often given for granted and therefore disregarded. If one traces the birth of macroeconomics down to Keynes in the aftermath of the Great Depression, then we must agree in saying that at that point stability was the issue. Keynes in fact envisages a world where substantial and long-lasting deviations from the equilibrium are not only possible, but rather frequent. The main message of the British economist is indeed that the system - left to itself - may not be able to return to the equilibrium once a perturbation has moved it from there. This belief informed economic theory (and a good deal of policy-making) until the $50 \mathrm{~s}$ and the $60 \mathrm{~s}$. With the emergence of the NAIRU hypothesis and its acceptance, the idea that a stable equilibrium existed regained momentum. In the last 30 years of so, in fact, economic theory has been giving for granted the ability of the system to be virtually always at equilibrium. Dynamic Stochastic General Equilibrium models describe the economy as peaceful stroll along the equilibrium path: from time to time small perturbations blur the picture, but built-in adjustment mechanisms put the system back on track with almost no lag. In this scenario, the role of any discretionary policy is at least questionable. Indeed, in a perfectly self-regulating environment there can be very little to gain if a bunch of government officials decide to mess with the machine in order to help it making its way toward the equilibrium. Most modern macroeconomics requires stability, i.e. that shocks to the optimal path are not going to force the economy further and further from equilibrium. If, for instance, current budget deficits do not simply usher higher future tax rates, but can lead to a debt crisis, then it is reasonable to expect that interest rates will jump up (in contrast with the standard neoclassic conclusion). Of course a debt crisis is not contemplated in this framework because the government cannot violate its intertemporal budget constraint. At this point we have done a full circle and are back from the beginning. Stability means that the economy has some built-in deviation-counteracting mechanism driving it back into the equilibrium path: once this is assumed, there is no need to consider the occurrence of a crisis, simply because this option has been deleted from the model. Hence the system is stable because there are no crises...

\footnotetext{
${ }^{3}$ Of course one needs to assume that credit ratings are a satisfactory indicator of default probabilities: although this may appear arguable, we will run the risk of maintaining this assumption.
} 
We don't want to push the argument too far. For our purposes it suffices to note that the existence of intertemporal equilibrium is conditional on the stability of the economic system. This seems to be an appropriate description of the European scenario, so that this hypothesis is not necessarily at odd with reality. The evidence put forward by Flandreau, Le Cacheaux, and Zumer (1998), for instance, suggests the presence of nonlinearities in market discipline: debtors are not going to feel any constraints on them unless they start stockpiling debt. In a sense we can say that stability, i.e. the ability to get back on track, is assumed by market participants for small deviations from the equilibrium. Once this boundary has been reached, it may well be that the same mechanisms work in the opposite direction and drive the system deeper into a crisis $^{4}$. In addition to that, we can say that the closer economic co-operation experienced by European countries and the adoption of a single currency can grant more resiliency to the economic system, enlarging the range of shocks for which the self-regulatory abilities of the economy work. In what follows we are therefore going to disregard externalities generated by financial crises and herding behavior. In sum, we have chosen to focus on spillover and not on contagion effects and do so by assuming that the provisions of the SGP were specifically designed to tackle the potential emergence of the former.

This section presents a taxonomy based on the distinction between models where the stock of government debt matters and models emphasizing the role of flow variables (budget deficits). We have chosen to concentrate on works that addressed the role of fiscal policy in an open economy with a fixed exchange rate regime, as this is the natural benchmark for EMU member countries. As it will become apparent, not always clear cut result emerge and - as it is often the case in economicsdifferent model specifications lead to different results. Thus we will see under which conditions does the theory predict fiscal policy to have international spillovers effects, in particular by affecting the world interest rate.

\subsection{Flow models}

We open our review with the classic Mundell-Fleming ${ }^{5}$ (MF) framework that has for long constituted the main workhorse of open economy macroeconomics. Despite its several limitations, among which there are the lack of microfoundations and its failure to distinguish among government consumption and investment (which makes it ill suited to study the effects of fiscal policy (Obstfeld and Rogoff 1996, p. 700)), the MF model is still regarded as a benchmark reference among professionals and academics. The MF framework postulates a simple income-expenditure keynesian model with interest bearing public bonds, fixed prices and demand-determined output. One consequence of the lack of any forward looking behavior is that no attention is given to intertemporal budget constraints and therefore to sustainability issues: hence there is no role for stock variables.

\footnotetext{
${ }^{4}$ This is the idea put forward by Leijonhufvud (1973) and labeled the 'corridor' hypothesis. Unfortunately, the issues risen in that article have not received much attention in the last 30 years.

${ }^{5}$ See Mundell (1963), Mundell (1964) and Fleming (1962).
} 
As it is often the case for open economy macroeconomic models, a distinction is drawn between the small country case and the full-fledged two-country model. The former assumes an economic system too small to affect world markets, so that prices and the interest rates are taken as given: fiscal policy then has no chance to impact on the these variables. This feature of the small open economy is obviously not peculiar to the MF framework but rather spans the whole literature, independently of other basic assumptions: in the rest of the section therefore we will focus only on two-country versions of all the models presented.

In the two-country MF model, a debt-financed increase in public spending bids the interest rate up independently of the direction of output changes (which can be positive or negative depending on the effect of the interest rate on world demand for domestic and foreign products).

The second class of models consists of the neoclassical (intertemporal) ones ${ }^{6}$ : here a representative agent with infinite horizon and perfect foresight maximizes her utility subject to a budget constraint. Perfect credit markets allow households to borrow and lend at the same interest rate as the government, which in turn levies lump-sum taxes and engages in public expenditures whose path is exogenously given. Under this set of strict conditions the interest rate, investment and consumption are invariant with respect to the way the government finances its expenditures: all that matters is the present value of government spending ${ }^{7}$. This result easily translates into an open economy framework: yet, while the irrelevance of the timing of taxes does not depend on size, size does matter for the timing of public expenditure $G_{t}$. Since the world economy cannot offset shifts of $G_{t}$ toward, say, the present by borrowing and lending (even though the present value of the infinite stream of government spending does not change) such a shift will put upward pressure on the interest rate as in the traditional keynesian model.

So far the government has not played any active role: by explicitly introducing government spending as a choice variable subject to an intertemporal budget constraint, we can actually study the effect of fiscal policy. Frenkel and Razin (1992) stress that there are two channels though which $G_{t}$ influences the equilibrium of the model: the absorption of resources that affects consumption and wealth, and the consumption tilting that depends on the intra- and intertemporal complementarity/substitutability between public and private consumption. Assuming that $G_{t}$ enters the utility function separably, one gets an intertemporal marginal rate of substitution independent of government spending and therefore shuts the latter channel

\footnotetext{
${ }^{6}$ For a comprehensive analysis of the role of fiscal policy in the neoclassical model see Barro (1989).

${ }^{7}$ Relaxing any of the basic assumptions, the predictions of the model change: 'Ricardian equivalence' between debt and taxes ceases to hold and 'traditional' outcomes on the interest rate emerge. For instance, by assuming finite horizons for households, one obtains that higher future taxes will be levied partly after the death of currently living agents, so that government spending has a wealth effect that increase present consumption, reduces saving and bids up the interest rate (the Ricardian result continues to hold in presence of intergenerational altruism: hence, more than finite horizons themselves, what matters is the degree of linkage across generations). Other extensions account for imperfect credit markets where different groups face different interest rates, uncertainty about future taxes and income streams and the presence of distortionary taxes.
} 
of influence. The absorption effect may produce different results according to the model setup: in case of a temporary increase in government spending the interest rate goes up as there is an excess demand for current goods; on the other hand a permanent shift in $G_{t}$ may lead both to a lower and to a higher interest rate depending on the marginal saving propensities of domestic versus foreign agents.

When we incorporate into the picture the distinction between tradable and nontradable goods, we get that the effects of government spending depend on two aspects: the intertemporal allocation of public versus private consumption and their commodity composition. In particular, if public expenditures are biased toward nontradables (as one would expect), the effects on the interest rate depend on the marginal saving propensities of the government and households, plus on the intertemporal elasticity of substitution of the latter.

Another way to break Ricardian equivalence is introduced by the third 'family' presented here: overlapping generation (OG) models à la Diamond (1965) and Blanchard (1985). The presence of individuals characterized by a finite horizon together with an infinitely lived society results in households using a different interest rate than the government to discount future events: therefore budget deficits do have a wealth effect. Frenkel and Razin (1992, chapter 11) present a two-period, twocountry OG model where a budget deficit results from a decrease in taxes holding the path of $G_{t}$ given. As anticipated, in this setup the timing of taxes does have an effect on the world interest rate, but while current deficits undoubtedly push it up, the impact of current and future deficits is less clear cut and depends on the comparison between the public and private saving propensities.

By introducing a third period into the model the authors are able to study the impact of a budget deficit on the term structure of interest rates. Their conclusions show that as long as the present value of government spending is held constant, expected future tax cuts increase the interest rate in the period of the deficit, while the short term (current) rate of interest will be affected only if domestic and foreign marginal saving propensities are different. Shifting now to the effect of changes in government spending, transitory variation in current $G_{t}$ bid up the interest rate along the entire maturity spectrum, while in the case of both transitory and permanent expected future changes, the direction of the interest rate shift depends once again on marginal saving propensities.

The last part of this section is dedicated to the new standard model in open economy macroeconomics, namely the Obstfeld and Rogoff (1996) (OR) framework. This is basically a sticky-price intertemporal model that combines keynesian features into a fully microfounded framework based on utility maximization. In the simplest case, government expenditure is considered pure waste (it affects neither productivity nor private utility) and displays no home-bias. While a temporary rise in $G_{t}$ has no effect on the interest rate $^{8}$, a permanent rise in world government spending actually reduces the short-term interest rates, thus reaching the opposite

\footnotetext{
${ }^{8}$ The reason is that output is demand determined: therefore an unanticipated temporary rise in $G_{t}$ results in a temporary rise in world output, with no effect on the amount of resource available to the private sector. See Obstfeld and Rogoff (1996, chapter 10) for the details.
} 
conclusion as the older MF model. The authors however warn that different ways to model public expenditure would lead to different predictions about the interest rate. Corsetti and Pesenti (2001), for instance, assume that government spending enters households' utility function and obtains the standard MF result whereby an fiscal expansion (domestic or foreign) bids up the world interest rate.

\subsection{Stock models}

There are a number of models predicting an active role for the stock of government debt: the first and foremost example that comes to mind is portfolio models where asset demand for bonds results from the maximization of a utility function subject to a wealth constraint. Tamborini (1997) provides an example referred to EMU member countries: investors allocate their wealth among two bonds issued by different countries in order to maximize an exponential utility function with constant absolute risk aversion. Despite the securities have symmetric statistical properties, Tamborini (1997) shows that in presence of different stocks of outstanding debt, an interest rate differential may develop as a result of the relative supply effect typical of portfolio analysis. This kind of models, however, determine interest rate differentials, not their absolute values and therefore are ill-suited to guide our empirical analysis.

Branson (1988) addresses the shift in the external position that characterized the US in the 1980s (and then Germany after unification): in so doing the author presents a two-country 'fundamental' model in the keynesian tradition where the domestic interest rate is determined via uncovered interest parity, adjusted by a risk premium. The latter depends on the relative size of domestic to foreign debt and so any fiscal deficit, by adding to the outstanding stock of debt, modifies the risk premium and therefore the interest rate. Branson (1988) considers a floating exchange rate regime and the impact of foreign deficits on the domestic interest rate depends on the sensitivity of the current account to the exchange rate. As this would be zero in the case of a monetary union, it is not clear whether the specification would produce the same outcome with a different exchange rate regime.

Branson (1988) introduces for the first time default risk into the picture: when that is taken into considerations, it is clear that the stock of debt matters. As we have anticipated above, however, credit risk will not be considered here on the ground that it is extremely unlikely that any European country defaults on its debt and that unless a country nosedives into debt, markets will not impose severe restrictions on its borrowing ability (including risk premia on bond yields) ${ }^{9}$. As it will become apparent by the rest of this brief literature review, however, there exists models in which default is not taken into consideration, yet the stock of debt does play a role of some sort.

First of all, Barro (1989) notes that, in open economy, invariance of equilibrium with respect of initial debt $B_{0}$ vanishes if foreigners hold part of it. This is because foreigners are not subject to future taxes levied to pay-back initial debt and

\footnotetext{
${ }^{9}$ See for instance Flandreau, Le Cacheaux, and Zumer (1998).
} 
therefore debt represents a free lunch for them. A related issue is the so called transfer problem: in a neoclassic intertemporal model initial debt positions (stocks) may affect the equilibrium world interest rate if the two countries display different marginal saving propensities. Yet this example holds the stock of initial world debt fixed and deals just with a redistribution of shares, so there is no role for an active policy.

In the two-country OG model presented in Frenkel and Razin (1992, chapter 11), higher levels of past public expenditure means a larger stock of initial debt for the current generation. The result is reminiscent of the transfer problem and the effect on the interest rate depends on the comparison between domestic and foreign marginal propensity to save.

Within the OG framework, Obstfeld and Rogoff (1996, chapter 3) describe a government that, starting from a zero net asset position, issues a give amount of debt and distributes it to the current old. Current and future young are then subject to taxes in order to keep the ratio of debt to the labor force constant. Savers must now acquire government debt as well as productive capital, with the result that the steady state capital stock will be lower (and the interest rate higher) than without debt.

Leith and Wren-Lewis (2001) introduce an OG structure in a new keynesian open economy model à la Obstfeld and Rogoff (1996). Since consumers are not infinitely lived, the rate of interest is different from their rate of time preference and it will be affected by the outstanding stock of government debt, which produces wealth effects.

Our review of flow models ended by noting that different ways to model government expenditure may lead to very different results. An interesting example is the paper by Aoki and Leijonhufvud (1987) where the authors present a characterization of investment whereby the return on capital (defined as the present value of the income stream resulting from the investment) depends on the stock of capital inherited from the past as well as on the rate of accumulation of new machinery. This is because a higher rate of investment and a larger stock of capital generate an increase of future production, which in turn implies an increase in future supply that is likely to drive down prices and revenues with them. Of course, to adapt this model to government consumption one needs to assume it (at least partly) to be constituted of investment goods and that such goods are substitute rather than complements to private investment. This represents a further example of how much modeling choices can affect final results and hence the policy implications of economic theory.

We conclude this section by discussing one last channel through which stocks may influence bond yields, namely liquidity. The marketability of a security in the secondary market may in fact be an important determinantn of bond yields and one expects diffusion to be closely related to the amount of outstanding assets. In a more sophisticated fashion, Gravelle (1999) calls this the effective supply hypothesis. Effective supply represents the amount of bonds in the hands of active market participants, i.e. investors that do not buy securities to hold them to maturity (the so called buy-and-hold investors). The author assumes a link between the stock of 
outstanding securities and liquidity via effective supply and trading activity. Empirical evidence presented in the paper supports this intuition: in the case of US government T-bills, in fact, turnover appears to be correlated with the outstanding stock of assets. The paper goes on claiming that when liquidity is proxied by the bond turnover ratio, there is evidence supporting the idea that

an increase in the size of the benchmark issue increases its liquidity (Gravelle 1999, p.29).

To reconcile the opposed forces of absorption and liquidity, we have to assume that while the negative impact on interest rates dominates in the case of the issuer country (i.e. the fall of the interest rate due to a larger issue is larger than its increase due to excess supply of bonds), the opposite holds for the foreign country. In other words, while the saturation effect spills over to all economies drawing from the same pool of savings (and so generates a generalized rise in interest rates), the liquidity effect is a local phenomenon ${ }^{10}$.

\section{Historical perspective}

In our quest for financial spillovers it is useful to turn back to the past and analyze some instances in recent European history when fiscal variables in one of the EMU member states moved in significant way. By focusing on such large swings, and by observing the concurrent movements in the yields on European bonds, we can establish a sort of benchmark episode to which subsequent, more ordinary dynamics can be compared.

Two events, in particular, will be considered here: German unification of 1990 and the Italian fiscal crisis of 1992. The two circumstances are of course neither of the same magnitude nor of the same relevance: the former is undoubtedly a onetime event whose consequences are not comparable to any other ordinary fiscal policy action; in the latter case, on the contrary, we do not observe a particularly virulent exogenous shock, but rather the sudden recognition that the Italian fiscal position was set on an unsustainable path. This awareness resulted in a dramatic fiscal tightening that generated the largest cut in public expenditure in Italian history, allowed Italy to move towards the fulfillment of Maastricht criteria and hence granted the country a seat among EMU 'first wavers'.

Analysis of the two events should of course provide us with different indications: the magnitude and persistence of the shock due to German unification is such that strong negative financial spillovers are expected to emerge and hit all European countries. In other words, if externalities exist this is one place where we trust them to show up. For what concerns the Italian crisis, it is clear that Italian rates were pushed up by the speculative attack on the lira of late 1992; the event did have

\footnotetext{
${ }^{10}$ Empirically, Cottarelli and Mecagni (1991) find that, during the 1970s and 80s, supply factors seem more relevant than risk indicators in pushing up the interest rate on Italian public debt. On the other hand, Codogno, Favero, and Missale (2003) conclude that international risk factors dominate liquidity in determining the yield spreads among EMU bonds.
} 
European-wide effects as it triggered a generalized realignment in EMS parities, but the the weak fiscal position of Italy is a candidate explanation for the peculiar movements of the Italian rates.

\subsection{German unification}

The purpose of this section is analyzing the international implications of German unification from a European perspective. At the end of the 1980s German represented the third economy in the world and played a pivotal role in the process of European integration. The European Monetary System had been established a decade before (1979), was basically centered on the DM and was used by many countries as a device to import monetary credibility from the Bundesbank ((Giavazzi and Pagano 1988)). Sound macroeconomic fundamentals made the yield on German long-term government bond the benchmark 'safe' asset for European investors.

For what concerns possible spillover effects, uncover interest parity (UIP) tells us that an interest rate differentials is explained by expectations about future exchange rate movements (or by country specific risk): in short we can write

$$
i_{t}-i_{t}^{*}=E_{t}\left[\dot{e}_{t+1}\right]+\rho
$$

where $i_{t}$ and $i_{t}^{*}$ are the domestic and foreign interest rates, $E_{t}\left[\dot{e}_{t+1}\right]$ the expectation about future movements in the exchange rate (price of foreign currency in terms of domestic currency) and $\rho$ is a country specific risk factor. Let us now take the vantage point of Italian investors and observe some of the consequences of German unification. Assuming that capital is freely mobile and that an increase in German deficit and debt puts upward pressure to the domestic interest rate, one should witness a capital flow from Italy to Germany, as Italian investors are attracted by the higher interest rate paid on German bonds. We can further imagine that a risk coefficient is attached to Italian government bonds, so that $\rho$ is larger than zero. Starting from an equilibrium characterized by a balanced CA, such financial flows will put upward pressure on the exchange rate, calling for an appreciation of the mark (and a consequent depreciation of the lira). Had this to actually occur, Italian investors holding German securities would experience a capital gain generated by the increased price of the foreign currency. To restore the equilibrium the Italian interest rate not only has to reach German levels, but has to climb even further in order to compensate the expected devaluation:

$$
i_{t}^{i t a}=i_{t}^{g e r}+E_{t}\left[\dot{e}_{t+1}\right]+\rho .
$$

This latter mechanism based on exchange rate expectation is obviously eliminated by a currency union: hence, on purely theoretical ground once a single currency circulates in different economic system, the chances for financial spillovers should be - ceteris paribus - lower.

In the second part of the section we will describe the developments in German public finances, external position and interest rates, while at the same time investigating the impact on interest rates of other European countries. The discussion 
is based on data from the IMF International Financial Statistics and the Deutsche Bundesbank Time Series Database.

There is little doubt that German unification required a massive disbursement on part of the Federal Government: although part of the required funds were collected by rising taxed and cutting expenditures in other sectors, integration of new Länder into market economy resulted in a surge of public deficit and debt. The Bundesbank (1997, p. 18) claims that this was partly due to the fact that

not only was the fiscal policy challenge associated with this [the unification process] unforeseen, its magnitude was also underestimated at first.

From the same source we learn that the ratio of debt to GDP jumped from under $42 \%$ in 1989 to over $60 \%$ in 1996 despite the positive impulse to production generated by unification itself ${ }^{11}$; in fact while between 1991 and 1993 nominal GDP grew at an average rate of $4.94 \%$, in the following three years growth was 'only' $2.78 \%$. The same applies to the deficit to GDP ratio that, thanks to robust production growth, never overcame the (in)famous $3 \%$ treshold imposed by the Maastricht Treaty ${ }^{12}$. To get a feeling of the magnitude of the amount of resources drained by unification we can look at few summary statistics: between 1985 and 1989 the average growth rate of public debt was $5.88 \%$, while the average deficit of the public sector amounted to less then 20 DM billion; over the years 1990-1994 the stock of debt grew at an average rate above $15 \%$ and excessive spending amounted to almost 60 DM billion on average. Table 1 displays information about some key macroeconomic variables before and after 1990: one important aspect that emerges clearly from the data is not only the magnitude, but also the length of the fiscal effort required by unification.

As we can infer from columns (4) and (5) of table 1, financing needs were met quite easily since foreign capital flew heavily into the country and kept coming for a long time after unification. This was facilitated by the increase in bond yields and by expectations about exchange rate dynamics (which would in fact be fulfilled in September 1992 with the EMS crisis). A glance to figure 1 gives an immediate idea of the dramatic turnaround in the external position of Germany: in the five years following unification the country imported capital at an average rate of almost 30 billion of dollars per year, for a cumulated financial inflow of roughly 150 billion. This stands in sharp contrast with what happened in the second half of the previous decade when German investors had exported an average of 48 USD billion each year.

So far we have repeatedly claimed that the process of integrating East Germany into Western standard implied an impressive and prolonged injection of resources on part of the public sector. Moreover, BoP data suggest that Germany absorbed

\footnotetext{
${ }^{11}$ In terms of debt to GDP ratio Germany is not the worst performer among European countries: in the same period, in fact, France and Italy display an even faster growth of debt relative to GDP. The economic expansion triggered by unification, together with the poor economic performances suffered by many European countries in the beginning of the 1990s can explain this apparent oddity.

${ }^{12}$ The Maastricht Treaty was of course not in place at the time of German unification: reference to its criteria is only made on a notional basis.
} 
resources from abroad and in particular from European countries that constituted Germany main trading partners. Table 2 reports the ratios of the German deficit to European GDP and to a European-wide stock of debt ${ }^{13}$. These figures provide us with some information on the incidence of the German fiscal shock on continental asset markets. While the deficit to GDP ratio has become a sort of benchmark measure of fiscal imbalances, the outstanding stock of debt proxies for market depth and should therefore indicate the ability of the market to absorb a give amount of bonds. Of course we expect a larger impact to cause a lager movement in European interest rates and hence, a larger negative financial spillover. To get a clearer picture we can use the Maastricht criteria to compute the notional limits on the ratios displayed in table 2 . Using some elementary algebra we can write

$$
\frac{\text { deficit }_{G e r}}{\text { debt }_{E U}}=\frac{\text { deficit }_{G e r}}{G D P_{G e r}} \cdot \frac{G D P_{G e r}}{d e b t_{G e r}} \cdot \frac{d e b t_{G e r}}{d e b t_{E U}}
$$

and

$$
\frac{\text { deficit }_{G e r}}{G D P_{E U}}=\frac{\text { deficit }_{G e r}}{G D P_{G e r}} \cdot \frac{G D P_{G e r}}{G D P_{E U}}
$$

where the first term on the right hand side of both equations is the deficit ceiling of $3 \%, G D P_{G e r} / d e b t_{G e r}$ is the inverse of the debt limit of $60 \%$, for $\operatorname{debt}_{G e r} /$ debt $_{E U}$ and $G D P_{G e r} / G D P_{E U}$ we use long-term averages of the German to European debt and GDP, which for the period $1970-1995$ are $19.41 \%$ and $31.67 \%$ respectively. In both cases we obtain threshold values that are just below $1 \%(0.97 \text { and } 0.94 \%)^{14,15}$.

Let us now focus on the behavior of long-term interest rates in Germany and in the other European countries. We expect the yield on German bonds to go up under the pressure of the fiscal shock determined by unification. The first rows of table 3 show the monthly yield on long-term German bonds between 1 and 36 months before and after unification: we take June 1990 — when the DM was formally introduced in former DDR as the legal tender - as the origin of our imaginary time line. One thing to notice is that unification come at the end of an expansionary period and hence it contributed to overheat the economy: the Bundesbank raised interest rates sharply in order to control domestic inflation (Dornbusch and Wolf 1992), and high demand resulted full capacity utilization and spurred new investment. From the table it emerges that German rates did not react immediately to the shock (one month after unification the yield on long-term bond is 30bp lower than one month before), but then the upswing is rather persistent: the average yield in the 18 months that followed unification is $124 \mathrm{bp}$ higher than the average yield prevailing in the 18 months that preceded June 1990. These two facts suggest the presence of rigidities

\footnotetext{
${ }^{13}$ The latter variable includes data for the 11 countries that joined EMU in 1999; Ireland and Portugal are excluded from the count of European debt due to data availability.

${ }^{14}$ These of course are not absolute values: since they depend on the relative weight of domestic GDP and outstanding debt, they are country specific.

${ }^{15} \mathrm{~A}$ different measures of the flow impact of German unification can be found in Tamborini (1997, table 3). It is given by the ratio of government net borrowing (GNB) to the sum of gross private savings in the EU12 countries (GPS12) and measures the absorption of EU savings due to each national borrowing need. German figures jump from 1.8\% (1986-1990) to 4.2\% (1991-1995).
} 
that may have hindered the adjustment and that unification was perceived as a permanent rather than a transitory shock.

Turning now to the other European countries, the bottom part of table 3 reports the yield on a weighted average of government bonds of European countries. Due to data availability the basket of countries that constitute our European sample is slightly different from previous analysis, where we used the first 11 countries to join EMU, and takes into consideration also non EMU countries like Denmark and the UK. Yields of different governments are weighted according to two different criteria: nominal GDP and a measure of trade linkages with Germany (imports on part of Germany). While the former represents a natural choice to determine the importance of different economic systems in a European-wide context (Sinn (1996) uses weights based on 1980 GDP figures), the latter method - giving more weight to countries more closely linked to Germany - should produce a European rate more prone to financial spillovers. What emerges from table 3 is that the European rate as well reacted with a lag to the shock of unification, but this time the upward pressure fades rapidly as the yield is back to pre-unification levels within 6 months from the event. Different weighting methods do not result in any difference in the behavior of the European rate. Figure 2 plots the difference between the the German and the European yields over the years 1988-1992 and gives therefore a pictorial description of the phenomena analyzed so far. Between June 1990 and Septembr 1992, when speculators drove the lira and the pound out of the EMS, the spread shows a small tendency to decline and only on the verge of the crisis does it jump back to the levels of the beginning of the 1990s. A number of considerations can be made at this stage: German unification occurred at a time when an expansionary phase was ending: as a result interest rates were already high and the spread with respect to German rates was reducing as investors privileged return over risk ${ }^{16}$.

To better understand the issue of spillovers from Germany to other European countries we analyze spreads vis-à-vis the German bond yield. As anticipated above, the latter have been since long playing a pivotal role in the market for government securities and most debt instruments issued by other European countries paid a premium over it. Table 4 presents average yield spreads of selected European countries: we consider not only future EMU members, but also the UK (one of the EU members that opted out of EMU) and Switzerland (which is neither member of the EMU nor of the EU). We expect that looser linkages with Germany result in smaller spillover effects. Their presence should provoke the spread to change only slightly as an increase in the German rate is closely followed by an analogous movement in foreign interest rates. In the limit, with a one-to-one spillover effect, the spread should not change at all. On the contrary, if national economies are insulated from external fiscal shocks, then the spread should decline (or increase, depending on whether it is a positive or a negative spread) in response to the increase in German rates caused by unification.

\footnotetext{
${ }^{16}$ It is a well known phenomenon in finance that in periods of recession there is a flight to quality: and that risk affect yields proportionately rather than additively (see for instance Codogno, Favero, and Missale (2003).
} 
The picture that emerges from table 4 is not homogeneous for all the countries examined. Grouping them according to the behavior of their spread we can say that Belgium, Ireland, Spain and, to a lesser extent France, display a marked decline of the premium paid over German rates. The same applies to Italy in the early aftermath of unification, while later on the Italian spread moves up again in response to the particularly weak fiscal position of the country, the latent fiscal crisis that was mounting, and the speculative attack that hit the lira in September 1992. Luxembourg increased its margin over the German rate and 2 years after unification its (negative) spread was still larger than the value of March 1990. This is taken as a reference point in order to shield from the possibility that markets had somehow anticipated unification and therefore bond yields prevailing one month before the formal introduction of the DM into former DDR are already uncommonly high. Austrian spread became negative after unification, then it climbed back to the values prevailing in March 1990, 3 month before unification. Dutch figures as well underwent only minor shifts: yet two years after unification the German-Dutch spread is nil, while 2 year before it amounted to 30bp. Portugal exhibits a puzzling dynamic that pushed up the interest rate spread vis-à-vis Germany; this tendency is only reversed at longer horizons, but it is nevertheless difficult to reconcile it with our analysis. Turning now to the UK, we again observe that the spread is sensibly reduced, both in absolute terms (along the time line) and in comparison to average values before German unification; the oddity here is represented by the fact that, while the pound underwent in September 1992 a speculative attack that forced its exit from the EMS, no sign of upward pressure on the British rates emerges from the data, but this behavior can be rationalized by observing that having followed a policy of high interest rates for more than two years (in order to comply with the narrow fluctuation bands imposed on the pound by the EMS), the Bank of England cut its discount rate in half as soon as it was driven out of the EMS. The marked difference with respect to Italy may be justified by the stronger macroeconomic fundamentals that characterized the British economy at that time and that resulted in the currency crises not to impact on long-term interest rates. The last country, Switzerland, constitute a sort of 'control group': given its historical neutrality and its peculiar role in international capital markets we expect German unification to have no effects on Swiss yields. In fact the negative spread between the latter and German ones became even larger and it takes 18 months to the spread to go back to the levels observed 3 months before unification, testifying that the increase in German rates did not produce any comparable movement in Swiss yields.

All in all, there seems not to be much evidence in support of the negative financial spillovers hypothesis. While it is rather clear that the German rates were shifted up by the fiscal shock due to unification, yield on long-term securities issued by other European countries do not display any marked tendency toward an increase. Spreads vis-à-vis German rates declined for most countries considered. To support this interpretation one can integrate exchange rate expectations into the picture and note that in presence of an expected appreciation of the DM, not only should European rates have moved upward, but they should have jumped higher than German ones as 
predicted by the UIP condition (1b). Hence in presence of an expected appreciation of the DM financial spillovers would not be the only determinant of any upward movement in other European interest rates. Despite a generalized consensus exists on the fact that the EMS crisis of 1992 was not anticipated by the market ${ }^{17}$, the realignment proposed by Germany as early as 1989 and the flexibility (albeit very limited) granted by EMS fluctuation bands suggest that the expected change in exchange rates could not realistically be set at zero and thereafter the limited upward movement of European rates is at least partially to be ascribed to exchange rate movements, thus giving even less support to the spillover hypothesis.

Moreover, many authors (see for instance Rose and Svensson (1994), Sinn (1996) and the references therein) claim that the EMS crisis that hit many European currencies in September 1992 was caused by German unification itself: in particular, the upward swing in German rates and the consequent flow of financial resources into the central European country called for a revaluation of the DM. Once France, the UK and Italy opposed to the realignment in fear of undermining the credibility of EMS (and the anti-inflationary credibility they were importing though it), real appreciation of the DM had to arrive through price changes. The liberalization of capital flows mandated by the Single European Act and implemented in most countries by the beginning of 1990 made impossible to reconcile fixed exchange rates and independent monetary policies. Thus a conflict emerged between the Bundesbank commitment to control domestic inflationary pressures, the sluggish economic performance of partner countries and their unwillingness to realign. This tension opened the door to a speculative attack and hence to the crisis with the resulting redefinition of central parities. This chain of events excludes any strong role for spillover effects on European interest rates: had they occurred, in fact, the flow of capital to Germany would have been limited, the need for revaluation not emerged and EMS band would have likely granted the system enough flexibility to face the shock. German unification is not the only culprit for the EMS crisis. In a classic contribution of the topic, Eichengreen and Wyplosz (1993) review four different explanations, do not find a great deal of support for the view that unification played a leading role, but nonetheless do present some evidence in this direction. Their conclusion privileges the explanation based on self-fulfilling expectations but still acknowledges that several other factors contributed in building-up favorable conditions for speculators to succeed ${ }^{18}$.

An alternative explanation for the lack of financial spillovers is that the latter were 'compressed' by accommodating monetary policies in European countries, unsustainable in light of the anti-inflationary stance pursued by the Bundesbank. While it is certainly true that a conflict between Germany and other countries emerged as the former economy was heating up under the stimulus of unification

\footnotetext{
${ }^{17}$ Rose and Svensson (1994) quote the behavior of interest rates — which did not jump up until the onset of the crisis - to corroborate this view.

${ }^{18}$ Their table 3 , for instance, presents the results of a survey of foreign exchange market participants: apparently $68.4 \%$ of respondents maintained that high German interest rates were the most important factor in determining realignment expectations.
} 
while Europe was sliding toward a recession, there seems to be little support for this hypothesis. Figure 3 and 4 display the the percentage change in money and money market rates for Germany, the UK and Italy. There is no evidence supporting the view that the British and Italian authorities pursued a particularly loose monetary policy in the period between German unification and the EMS crisis.

\subsection{Italian fiscal crisis}

The analysis of the Italian experience of the early nineties is complicated by the fact that the (potential) fiscal crisis suffered by the country is intertwined with the speculative attack that between September 16th and 17th forced the British pound and the lira out of the EMS. Mainly for this reason, in this section we will use a nontechnical approach that exploits economic intuition rather than statistical inference; despite the fact that our conclusions are therefore not corroborated by the bells and whistles of econometrics and may appear not to be solidly grounded, we believe this short parenthesis can provide us with some interesting information in our search for financial spillovers.

In the present section we will review the development of Italian public finances that led to a (potential) fiscal crisis that erupted at the beginning of the nineties, almost in correspondence of the speculative attack on the EMS of September 1992.

Some sort of consensus exists in the profession on the notion that the crisis of 1992 was not driven by fundamentals: in fact, as Rose and Svensson (1994) show, shortterm interest rates remained fairly constant until late August and did not display the sharp increase resulting from rising expectation of depreciation predicted by models of currency crisis based on unsustainable BoP positions ${ }^{19}$. This observation gave rise to another family of models ${ }^{20}$ in which multiple equilibria exists and expectations play a major role in determining the crisis (Obstfeld 1996). While this kind of models accommodate currency crises that hit countries with sound fundamentals (as it was the case of the UK in 1992 and Mexico in 1994), it is important to note that economic systems displaying weaker positions are more vulnerable also to crises driven by 'sunspot equilibria': this is exactly what happened to Italy in September 1992.

Deterioration of Italian public finances begun in the 1970s as a consequence of the oil shocks that severely hit an economy traditionally dependent on oil imports. Public expenditures quickly showed a large degree of hysteresis and governments were not able (or not willing) to adjust them when the international situation improved. Thus the debt-to-GDP ratio grew from 34\% in 1970 to almost 50\% in 1975 and $55 \%$ in 1980, despite the fact that in the second half of the decade real GDP had grown at an average rate of $4.46 \%$ and therefore there was presumibly little need to sustain it. The same bahavior characterized the 1980s: relative to GDP, the stock of debt grew to reach $95 \%$ in 1990, whith two-digit fiscal deficits occurring year after year. To get a complete picture of the disastrous state of Italian public finances at

\footnotetext{
${ }^{19}$ The so-called first generation models à la Krugman (1979) and Flood and Garber (1984).

${ }^{20}$ Labeled second generation models.
} 
the beginning of the nineties, it is useful to look at yet another indicator, namely the ratio of interest rate payments over GDP. This represents the self-reinforcing part of debt: since to higher levels of debt corresponds larger interest outlays, the primary surplus needed to at least stabilize debt is greater and the this in turn increases the risk to observe a vicious circle running from debt and interest payments to deficit and hence debt. Had something of this sort to happen, then drastic measures need to be taken, which can even result into debt consolidation or repudiation. Table 5 reports some widespread fiscal indicators for Italy: note that the amount of resources devoted to pay interest on the outstanding stock of debt grew at an alarming pace and at the beginning of the nineties seems to have taken an explosive path. In fact, in the short time span ranging from 1990 to 1992 the debt-to-GDP ratio gained other 10 points and the share of national GDP absorbed by interest outlays moved from below $10 \%$ to above $12 \%$, witnessing a critical situation that could easily go out of hands ${ }^{21}$.

The response of long-term bond yield to the development of Italian public finances occurred in two stages: as the top-left panel of figure 5 shows, the Italian interest rate jumped up a first time in the first quarter of 1991 - most probably a reaction to the cumulative deterioration of that country's fiscal position - and then again in correspondence of the speculative attack. The very week that saw the eruption of the currency crisis, the Italian government eventually adopted drastic fiscal measures by passing budget cuts that amounted to nearly 100 trillion liras (around 7\% of 1992 nominal GDP, the largest budget cut in Italian history) and taking a formal commitment to meet Maastricht criteria in time to join the EMU together with the first group of countries. This timing prevented the situation to get worse and made the interest rate increase short lived, allowing yields to take a descending path that lasted until the beginning of 1994.

The other panels of figure 5 display bond yields for a selection of European countries. The British and French rate do experience small increments around the time of the crisis, but they are very small compared to the jump undergone by the Italian rate and should mostly be attributed to exchange rates expectations ${ }^{22}$. In fact both countries were experiencing a downward movement in interest rates before the crisis: the speculative attack provoked only a small temporary pause in this pattern, which quickly regained its pace afterward. Surely, sound public finances did play a role in limiting the impact of the EMS crisis on bond yields by eliminating the increase due to default risk (the main determinant of the different behavior of Italian rates). The three bottom panels of 5 show the path followed by German, Dutch and Austrian interest rates. While the first yield display a small increase at the time of the crisis (we have to remember that Germany as well was characterized by a fiscal position that was getting weaker as a result of unification), this had almost no impact on the latter two countries ${ }^{23}$.

\footnotetext{
${ }^{21}$ In an interview given on February 25th, $1993 \mathrm{Mr}$. Ciampi - at that time Governor of the Bank of Italy - stated that in Fall 1992 the country had been close to a financial collapse.

${ }^{22}$ Note that the scale of the Y-axis is different for different panels of figure5, hence visual comparison of interest rate levels may be misleading.

${ }^{23}$ Austria was not formally a member of the EMS but was rather pegging its currency to the
} 
Overall, while the speculative attack of September 1992 did have European-wide effects on interest rates by forcing a generalized realignment of fixed parities among currencies participating to the EMS, no clue emerges of any negative spillover accruing from the fiscal crisis that hit Italy in the same period. While it is rather difficult to disentangle the movements in bond yields due to expected devaluations from those generated by fiscal fundamentals, it appears that the crisis had a larger impact on countries characterized by weaker public finances. This behavior witness to the ability of markets to correctly discriminate among issuers and provide some other evidence (though almost anecdotal) against a significant role of negative financial spillovers.

\section{Empirical analysis: aggregate behavior in the euro area}

Turning now to more formal empirical analysis, the search for potential spillovers of fiscal policies on the European interest rate crosses with tests of the Ricardian equivalence hypothesis that we have encountered in section 3.

One of the traditional channels identified in the literature for testing Ricardian equivalence addresses the relation between fiscal deficits and interest rates ${ }^{24}$ : the amount of research devoted to the issue is extremely vast ${ }^{25}$, though empirical evidence is confused and gives mixed results. Recent examples of works reaching opposite conclusions include Laubach (2003), Gale and Orszag (2003) and Kormendi and Protopapadakis (2004).

Recently some authors have taken a slightly different route and have investigated the impact of world fiscal variables on interest rates. The parallelism with the issue of financial spillovers is straightforward. Indeed, Ford and Laxton (1999, pp.7778) explicitly claim that with globally integrated capital markets it is world debt that matters for the determination of country-specific interest rates. Hence, they continue, 'countries with high levels of government debt may be imposing negative externalities on others'. The fundamental hypothesis at work here is that a euro cent of debt has the same impact on world markets regardless of the issuer. The conclusion of the two authors is that the ratio of OECD public debt to world GDP has had a substantial effect on the interest rates of nine industrial countries ${ }^{26}$ over the period 1977-1997. Local developments, on the other hand, are only relevant to explain persistent spreads, though their effect is not significant on interest rate levels.

Breedon, Henry, and Williams (1999), who study G-3 economies over period 1975-1988 using ex-post 10 year real interest rates, present similar results even if

\footnotetext{
DM in an informal manner.

${ }^{24}$ Yet one has to recognize that it is possible to observe no correlation between fiscal variables and interest rates for reasons that have little to do with Ricardian equivalence.

${ }^{25}$ Seater (1993) is often regarded as the main reference on the topic, though it is somehow dated.

${ }^{26}$ Belgium, Canada, Denmark, Germany, the Netherlands, Japan, Switzerland, the UK and the US
} 
they find a more relevant role for domestic factors that - they claim - are at least as important as international ones. The three authors interpret their result as evidence against financial markets integration.

Chinn and Frankel (2003) repeat the exercise investigating the impact of G7 debt on the interest rates of Germany, France, Italy and Spain over the period 1988-2002, but they find no significant effect.

Ardagna, Caselli, and Lane (2004) investigate the relation between fiscal variables and long-term interest rates using a panel of 16 OECD countries over the last 40 years. Their findings support the idea international factors are relevant (so that negative financial spillovers do occur), yet to a much lesser extent than domestic ones. Again, this evidence points toward a lack of integration in capital markets. Closely related to our work is the finding by the authors that EMU does not constitute a breakpoint for European countries: the introduction of the single currency in fact seems not to have resulted in international variables to be more relevant and/or domestic ones to loose importance in the determination of bond yields. In sum, this recent work suggests that while there is an effect of international fiscal variables on interest rates, the inception of EMU has not provoked any structural change in the relation between deficit, debt and bond yields.

Following Chinn and Frankel (2003) we test the hypothesis that European capital market can be considered as a single pool of funds from which all countries draw and for which they all compete. Once confirmed by the data, this theory would back the idea that by absorbing a significant share of European saving, the fiscal imbalances in one country can affect the common interest rate and thus impose negative externalities on economic partners. Yet, the budget limits incorporated into the SGP are not aimed at limiting European-wide fiscal expansions, but rather the behavior of single states. The relevant hypothesis is therefore more stringent than the one tested here, where we check whether European imbalances have an impact on the EMU-wide rate of interest. In other words a failure to reject our null hypothesis does not immediately lend support to the existence of negative financial spillovers as postulated in the SGP.

In this first empirical exercise we consider the euro area as a single economic entity and look for a relation among aggregate measures of the fiscal stance and a weighted average of different bond yields. We exploit two sets of data, both of which report figures for the 12 EMU countries as a whole: first we use quarterly data on the EMU published by OECD in its Economic Outlook for the period 1980q1 to 2004q2, then - in order to isolate the effect of EMU - we turn monthly data taken form the ECB Monthly Bulletin that range from January 1999 to April $2004{ }^{27}$.

In the actual implementation of the analysis we follow the structure suggested by Ardagna, Caselli, and Lane (2004) and incorporate some of the intuitions put forward by Kormendi and Protopapadakis (2004): we investigate both real and nominal bond yields, and do not restrict our attention to them, but also explore the

\footnotetext{
${ }^{27}$ The size of this second sample is rather small, and this surely affect the quality of estimates: yet we are looking for preliminary clues, rather than exact relations and so this admittedly rough evidence can furnish us with some guidance
} 
potential impact of fiscal imbalances on the current account, which should work as the main equilibrating mechanism if capital is fully mobile. In the case of the EMU, while there are virtually no residual barriers to capital mobility between member states and the rest of the world, a significant degree of portfolio home bias still remains, which makes the degree of openness somehow opaque. Then we can expect that if deficit neutrality is violated, both the interest rate and the current account would bare some responsibility of adjustment.

\subsection{Quarterly data}

In this first part of the analysis we exploit quarterly data for the EMU area as a whole published by the OECD. The data span the period between the first quarter of 1980 and the second of 2004 for a total of 98 observations. We have opted for the simplest possible specification, and therefore the basic estimating equation take the form:

$$
Y L D_{t}=\varphi_{0}+\varphi_{1} t+\varphi_{2} \frac{\text { surplus }}{G D P_{t}}+\varphi_{3} \frac{d e b t_{t}}{G D P_{t}}
$$

where $Y L D$ is an average real (nominal) yield on long-term bonds issued by EMU area governments, $t$ is a time trend and surplus the primary balance ${ }^{28}$. As a robustness check we introduce a second measure of the fiscal position specifically aimed at capturing the non-anticipated part of the fiscal stance. This variable, which appear as fiscal in the tables, is constructed following Blanchard (1990),Brunila, Hukkinen, and Tujula (1999) and Farina and Tamborini (2002) and basically reports the fiscal stance net of cyclical effects; in other words it is an indicator of discretionary fiscal policy.

Its construction is fairly easy: the first step is running a regression of the primary balance to GDP ratio $(P B)$ on a constant, a time trend and GDP growth $(G \dot{D} P)$

$$
P B_{t}=\lambda_{0}+\lambda_{1} \text { trend }+\lambda_{2} G \dot{D} P_{t} ;
$$

then estimated coefficients are used to build a growth adjusted primary balance $(G A P B)$, which is obtained by inserting the previous period GDP growth rate into the estimated equation. This variable represent which is the primary balance that would have prevailed in period $t$, had the GDP grown at the same rate as in period $t-1$. This is computed as

$$
G A P B_{t}=\hat{\lambda}_{0}+\hat{\lambda}_{1} t+\hat{\lambda}_{2} G D P_{t-1}
$$

while our fiscal stance indicator is simply given by the difference between the growth adjusted measure and the observed value of the primary balance

$$
\text { fiscal }_{t}=G A P B_{t}-P B_{t-1} .
$$

As it is for surplus, a positive value of fiscal implies a fiscal restriction.

\footnotetext{
${ }^{28}$ Hence we expect the coefficient on this variable to be negative as an increase in the primary balance should lower the borrowing cost faced by the government.
} 
Table 6 presents results for estimation of equation 2 in levels. The first two sets of estimated coefficients tell that fiscal imbalances do not have any impact on real bond yields, regardless of the variable used (either the primary balance or the measure of discretionary policy à la Blanchard), whilst the stock of outstanding debt has a significant effect on the cost of borrowing, most probably via risk premia. The table then reports results for a new specification in which a dummy for the EMU is included and interacted with fiscal variables to check the hypothesis that the introduction of the single currency marks a break in the data so that after 1999 deeper integration of European capital market results in EMU fiscal variables having a larger impact on bond yields. Interaction terms are indeed significant and suggest that monetary integration may in fact have increased the importance of euro-area variables in determining interest rates. In particular, the primary balance to GDP ratio (interacted with the EMU dummy) is positive, contrary to what theory suggests, while the stock of debt is negative. The latter interesting result tells that after 1999 liquidity effects dominate default risk consideration: financial markets ceased to discriminate among EMU members sovereign issuers and as the amount of outstanding debt increases, bond yields are pushed down by the increased liquidity of the securities.

One major caveat applies to these estimates: as unit root tests cannot reject a null of nonstationarity for most of the variables involved in the regression, results may be spurious. This suspicion is confirmed by residual-based tests for cointegration $^{29}$ : regression residuals from equation 2 -considered as the cointegrating relation - are not stationary and therefore point toward the lack of any long-run equilibrium relation.

To address the issue of nonstationarity we therefore run the same regression in first differences and display the results in table 7 . Estimated coefficients change dramatically and loose significance: more importantly, the ratio of debt to GDP now changes sign and gets negative, albeit it is not significant at $10 \%$. Again, the situation does not improve if we substitute fiscal to surplus. Interacting fiscal variables with the EMU dummy does not improve the situation much: coefficients are positive, but not significant, so the inception of the monetary union seems not to have had a strong impact. A further step consits in augmenting the estimating equation with the squares of fiscal variables (primary balance and debt to GDP): this should capture nonlinear effects on bond yields, but again results are not significant. Thus table 7 tells that bond yields are not determined by fiscal variables.

To check the robustness of our (non-)results we have also analyzed nominal bond yields. We keep using the differenced form of equation 2 but include inflation among the explanatory variables ${ }^{30}$. The first row of table 8 shows that inflation has a positive impact on bond returns, the primary deficit continues not to exert any influence on bond yields, while the coefficient of stock of debt is now negative and significant. This suggest that liquidity effects dominate default risk consideration

\footnotetext{
${ }^{29} \mathrm{ADF}$, Phillips-Perron and KPSS tests.

${ }^{30}$ One would ideally use inflation expectations over the life of the bond; lacking this kind of data we proxy them with the contemporaneous inflation rate.
} 
and reverse findings obtained estimating the equation in levels. Also, either when deficit and debt variables are interacted with the EMU dummy (results are not significantly different) or their squares are introduced in the equation, the main message is the same.

A further check is performed by using the difference between the yields on longand the short-term bonds as the LHS variable. While this should eliminate some noise from the data, there is the drawback of the limited time span for which the short-term interest rate is available and that results in only 57 available observations. Results (not reported) are not satisfactory as no explanatory variable is significant and a join F-test cannot reject the null of all the coefficients being equal to zero.

Turning now to the current account, the basic estimating equation becomes:

$$
\frac{C A B_{t}}{G D P_{t}}=\vartheta_{0}+\vartheta_{1} t+\vartheta_{2} \text { inflation }+\vartheta_{3} \frac{\text { deficit }_{t}}{G D P_{t}}+\vartheta_{4} \frac{d e b t_{t}}{G D P_{t}}
$$

where variables have a straightforward interpretation. Table 9 reports estimated coefficients and standard errors for this specification. Inflation has a negative effect, as a rise in domestic prices lowers competitiveness and depresses exports; the debt to GDP ratio is negative but not significant while it is interesting to see how different measures of the fiscal stance brings about opposite results. The negative coefficient obtained using the primary deficit becomes positive (and has almost the same magnitude) when the indicator for discretionary policy is introduced. This would imply that a fiscal tightening is associated with an increase in bond yields and therefore runs against theory and common sense.

The issue of nonstationarity emerges also in the case of the current account. Again, as all the series display a unit root we hypothesize that equation 5 may serve as a cointegrating relation and test the estimated residuals for unit root. Both ADF and Phillips-Perron test reject nonstationarity at $10 \%$ and therefore lend some credit to the hypothesis of cointegration. Then however OLS are not adequate and we have to disregard estimates presented in table 9 . We then proceed with the estimation of equation 5 by dynamic OLS (DOLS) and dynamic GLS (DGLS) as suggested by Stock and Watson (1993). Unfortunately fiscal variables are not significant and thus DOLS and DGLS results contradict residual-based tests for cointegration.

\subsection{Monthly data}

In order to focus on the impact of EMU we now restrict our attention to the period that followed the introduction of the single currency: to cope with this short time span we have to resort to monthly observations compiled by the ECB and therefore, instead of analyzing the impact of public deficits on bond yields, we concentrate on the issuing activity on part of the public sector (data on fiscal variables only exist at lower frequencies). This 'restriction' has the additional benefit of allowing for a direct test of the hypothesis that the absorption of saving by the pubic sector - rather than fiscal variables per se- is what really matters for the determination 
of bond yields. Our baseline specification for the real interest rate and the current account balance are:

$$
\begin{aligned}
\Delta Y L D_{t} & =\gamma_{0}+\gamma_{1} t+\gamma_{2} \frac{i s s u e_{t}^{g}}{G D P_{t}}+\gamma_{3} \frac{i s s u e_{t}^{p}}{G D P_{t}}+\gamma_{4} \Delta \frac{\text { stock }_{t}^{g}}{G D P_{t}}+\gamma_{5} \Delta \frac{\text { stock }_{t}^{p}}{G D P_{t}} \\
\Delta \frac{C A B_{t}}{G D P_{t}} & =\psi_{0}+\psi_{1} t+\psi_{2} \frac{i s s u e_{t}^{g}}{G D P_{t}}+\psi_{3} \frac{i s s u e_{t}^{p}}{G D P_{t}}+\psi_{4} \Delta \frac{s t o c k_{t}^{g}}{G D P_{t}}+\psi_{5} \Delta \frac{\text { stock }}{G D P_{t}}
\end{aligned}
$$

where $Y L D$ is the real/nominal yield on a government benchmark bond while the superscripts $g$ and $p$ identify for the public and private sector respectively.

Many variables are nonstationary and thus enter the estimating equation in first difference. Euro area yields are calculated on the basis of weights corresponding to nominal outstanding amounts of bonds in each maturity. Real yields are deflated $e x$ post using the harmonized consumer price index. Our dataset consists of monthly observations from January 1999 to April 2004 for a total of 64 observations $^{31}$. We do not focus on a single maturity but rather use both 3 and 10 year bonds in order to span the yield curve. This is intended to give some information on the nature of spillovers: while in fact according to the absorption hypothesis bonds of all maturities should be affected by an increase in the issuing activity of the public sector, the spillover would occur only at longer time horizons were the driving force to be credit risk. Interpretation of equations 6 and 7 is straightforward: under the 'standard' view either the real rate or the current account balance should be affected by the absorption of resources by the public and the private sector. In addition, the basic equations are augmented with the introduction of GDP growth ${ }^{32}$ that should capture responses of the interest rate (and of the current account) to the business cycle, while when nominal yields are used on the LHS, CPI inflation is added to the regressors.

Tables 10 and 11 report results for real yields on 3 and 10 year benchmark government bonds. The first set of parameter estimates and t-statistics refer to equation 6 , while the last two columns report estimation results when GDP growth is included. Durbin-Watson statistics suggest the presence of autocorrelation among the residuals: this is confirmed by Ljung-Box Q test and has lead us to compute Newey-West HAC standard errors, from which t-stats are computed. As one would expect, the short-term yield is more sensitive to business cycle fluctuations represented by GDP growth; interestingly, something similar occurs to the stock of private debt which also has a positive impact on bond yields once GDP growth is included. During economic upturns interest rates go up and as the private sector increases its stock of debt, corporate bonds will bear a higher risk premium that pushes up returns. This, combined with return-seeking behavior on part of investors (typical of economic growth phases) may explain why a higher stock of private debt spills over to government benchmark bonds: in order to attract savers, public securities have to offer a higher return to cope with what happens on the corporate bond market. In

\footnotetext{
${ }^{31}$ Data are taken from the ECB Monthly Bulletin, which is the reference for more information on the data.

${ }^{32}$ Derived from interpolated quarterly data.
} 
sum, table 10 and 11 suggest that at shorter maturities it is as if private and public debt are less segmented due to the risk seeking behavior of investors. This effect is much less pronounced at longer horizons: table 11 in fact show that neither GDP growth nor the stock of private debt are significant at 5\%. Bond issue to GDP as well is not significantly different from zero at all maturities.

Turning now to nominal yields, tables 12 and 13 display a similar (and stronger) pattern. Inflation has a positive impact on bond yields and the stock of private debt is strongly significant regardless of the inclusion of GDP growth. Table 13 in particular displays t-statistics that are much larger than those reported before and variables are often almost significant: the issuing activity of has a positive impact on the yield while the negative sign of the stock of public debt points toward the prevalence of a liquidity effect whereby the return on bonds is lowered by an increased marketability. The fact that government issue gains significance in the 10 year segment would suggest that the impact of public deficits on bond yield works through default risk rather than absorption of saving. In fact, given current credit ratings, the likelihood of default is very limited for all EMU members and fiscal imbalances probably affect only marginally default probabilities, and only long-term ones. On the contrary, the excess supply phenomenon associated with an issuer absorbing a significant share of saving should impact bond yields across the whole maturity spectrum.

Table 14 reports results obtained testing equation 7, where the dependent variable is the current account balance as a share of GDP. Kormendi and Protopapadakis (2004) maintain that in an open economy framework, any effect of public deficits on interest rates is not backed by any theory; rather, one would expect the current account balance to move, as the economy should attract foreign capital to finance its deficit. Hence, many of the studies that do not find any support for the standard crowding-out hypothesis may fail because they look in the wrong direction. Unfortunately, results are very poor, estimated coefficients never different from zero and the negative values for the adjusted $R^{2}$ summarize the inadequacy of the model. Moreover, a joint F-test does not reject the null hypothesis of all the coefficients being equal to zero. Thus, the absorption of resources by either the private or the public sector does not appear to have any impact on the current account balance.

Overall, the empirical analysis does not provide much credit to the hypothesis that the fiscal position of the euro area as a whole affects either bond yields or the current account. This is consistent with recent evidence put forward by Breedon, Henry, and Williams (1999), Chinn and Frankel (2003), Kormendi and Protopapadakis (2004) and Ardagna, Caselli, and Lane (2004). On the other hand, the results obtained in the case of 10 year bonds (tables 11 and 13) may be read as a sign that at longer maturities some sort of linkage exists between public finances and real interest rates. Hence the relevant channel would be credit risk, which can be expected to affect (albeit marginally) only long-term contracts given the low probability of any EMU member country defaulting on its debt in the near future. 
Analysis of current account data appears to be dominated by noise. The specification chosen for the analysis, which is consistent with theory and is consistent with other works on the issue (see for instance Kormendi and Protopapadakis (2004)) finds not support in the data and the main message is one of no relation between fiscal stock and flow variables and the current account balance. There are a number of possible explanations for this result: first the EMU is not exactly a small player in international capital market so that it poorly fits a theoretical framework designed to fit the small country case, second capital market may not be perfectly integrated, especially when we consider interaction with extra-EMU countries, so that bond returns differentials are not eliminated by arbitrage.

\section{$6 \quad$ Linkages among EMU member states}

This section goes deeper in the empirical analysis by narrowing the focus on the linkages among government bonds issued by EMU members. Recently there has been a surge of interest on the dynamics of European government bonds market ${ }^{33}$. The latter is often regarded as the most important financial market, as government securities do not merely represent the dominant financial instrument in European portfolios (Perée and Steinherr 2001), but rather perform a number of tasks related to the economic well-being of the society (Gravelle 1999). Moreover, different authors agree in identifying the bond market as the financial market segment that has more promptly reacted to the inception of the EMU and that has most remarkably integrated to form a single pan-European market.

Most studies focus on spreads among securities issued by different European states, trying to detect their main determinants now that, with the elimination of exchange rate risk, segmentation should decline and assets become closer substitutes. In presence of spillovers, however, it is not possible to assess whether spreads reflect correctly priced risks and so the strategy has to be adjusted ${ }^{34}$.

Codogno, Favero, and Missale (2003) investigate the behavior of relative asset swap spreads (RAS) with respect to Germany; RAS defined as the difference between the bond yield spread and the spread on swap rates of the same maturity, represent the component of the yield differential not related to exchange rate factors and thus allow the authors to pool together data for both the period before and after 1999. Empirical evidence suggests that international risk factors dominate liquidity, while no role is played by different debt to GDP ratios.

Hartman, Maddaloni, and Manganelli (2003) agree on the point that remaining

\footnotetext{
${ }^{33}$ See among others Lemmen and Goodhart (1999), Lønning (2000), Camarero, Ordoñez, and Tamarit (2003), Hartman, Maddaloni, and Manganelli (2003), Codogno, Favero, and Missale (2003), Bernoth, von Hagen, and Schuknecht (2004), Dunne, Moore, and Portes (2003), Afonso and Strauch (2004), Piga and Valente (2004)).

${ }^{34}$ If the interest rate faced by a country depends on all other EMU countries' behavior it is not possible to assess whether a lower yield spread between, say Italian and German bonds depends on the strengthening of the Italian fiscal fundamentals, or rather on the effect of a weak Italian position on German yields (or on a mixture of the two effects).
} 
spreads cannot be explained by credit risk differentials and judge the fact that prices of bonds with identical ratings have not fully converged as a legacy of market segmentation. According to their view, this hypothesis is backed up by the fact that quantity-based indicators show a still significant home-bias in European portfolios (though it has diminished after the introduction of the signle currency).

Afonso and Strauch (2004) study the impact of 2002 fiscal policy events on default risk (measured by the spread between the swap rate and the yield on bonds of the same maturity). They use daily data for the same year and their findings witness to the lack of a strong reaction. This is consistent with the interpretation that with current credit ratings default risk is negligible for almost all EMU member countries and therefore corroborates our decision to disregard this channel.

Dunne, Moore, and Portes (2003) analyze interactions among German, French and Italian bonds. They exploit two different techniques to look for a benchmark security, i.e. the instrument to which the price of other securities react. First, focusing on short-term dynamics, they use a VAR in levels and find that in the long-term segment of the market the return on Italian securities Granger-causes the yield on German and French ones, but highlight potential problems in their dataset (they use intra-day data, so that most actively traded securities may appear to Granger-cause other assets suffering from the stale price problem). Therefore they address long-term equilibrium relations exploiting cointegration analysis and find that German bonds emerge as the benchmark.

\subsection{Linkages across bond yields}

Figure 6 plots the yields on 10 year government bonds for the 11 countries that joined EMU in 1999: the graph spans the period between January 1990 and June 2004 and displays monthly averages of long-term bond yields ${ }^{35}$. Two facts emerge: first, a dramatic convergence process took place between 1995 and 1997 and was almost completed before the actual introduction of the single currency; second, it is clear that yields on bonds issued by different European countries move together. This is striking since 1999, but even at the beginning of the sample there was a marked tendency to co-move.

Does this imply the existence of financial spillovers? Not necessarily: according to Dunne, Moore, and Portes (2003) and their definition of the benchmark asset, we need to distinguish financial spillovers from long-term equilibrium relations that link different financial instruments in the same market. Empirically, this entails addressing short-term dynamics rather than long-term analysis, i.e. taking the opposite route from Dunne, Moore, and Portes (2003). This is consistent with what suggested by Favero (2001), who notes that in recent research VARs in levels rather

\footnotetext{
${ }^{35} \mathrm{~A}$ legend is missing from the figure as distinguishing 11 series in a black and white plot is a desperate task, therefore we decide to skip it altogether; note, however, that knowing which is which makes absolutely no difference for our discussion and thus we prefer to plot all the series in order to get a complete picture rather than presenting only a selection of countries that would grant a neater graph.
} 
than Vector Error Correction Models are used when the focus is on short-run dynamics, regardless the presence of nonstationary variables and cointegrating relations.

The first halt in our search for financial spillovers is then a VAR in levels with subsequent Granger-causality tests. We concentrate on the period that followed the introduction of the euro as spillovers should emerge more clearly once exchange rate risk is eliminated; we exploit a dataset comprising daily observations on 10 year bond yields from January 2001 to June 2004. Results (not presented and available upon request) show that Granger-causality is never rejected for all variables and all equations and suggest that there is in fact co-determination of bond yields.

This being established, we are left with the main part of the problem yet unsolved: we need to determine the source of such interactions among government securities. The negative financial spillover hypothesis suggests that at least part of the co-movements are due to externalities stemming from the fiscal position of EMU member states. Theory therefore provides us with some guidance and directs our analysis toward the potential impact of domestic fiscal imbalances on foreign interest rates.

\subsection{The role of fiscal policy}

Our first move at this point is collecting a set of auction dates for Italian 10 years bonds: these are auctioned once a month following a predetermined calendar. We then build a dummy variable that simply takes value 1 in correspondence of auction days and zero otherwise and add it to the VAR specification, both in linear form and interacted with the issue size. Not surprisingly, this first attempt yields no interesting results. Even after interacting the dummy with the amount of securities auctioned that day, results are very poor (the dummy variable is significant only once, namely in the equation describing the Dutch bond yield). As auction dates follow a predetermined calendar and issuing institutions are more and more careful not to flood the market with unwanted securities (the amount actually allocated to investors falls short of demand in all occurrences we observed), one could expect auctions dates and sizes not to be good proxies of the absorption effect determined by fiscal imbalances.

In order to analyze the impact of fiscal variables on bond yields, it is necessary to move to lower frequencies. In what follows we will once again exploit both quarterly and monthly data. These are still rather high frequencies in terms of fiscal indicators and we are going to pay a cost in terms of available series (and maybe their reliability). On the other hand the time span on which we can concentrate is not very large and these data allow us to maximize the number of available observations ${ }^{36}$.

Our empirical specification draws from recent works on the topic, especially Afonso and Strauch (2004), Bernoth, von Hagen, and Schuknecht (2004) and Ardagna, Caselli, and Lane $(2004)^{37}$. The latter is especially interesting as it develops a very

\footnotetext{
${ }^{36} \mathrm{~A}$ large part of our analysis is driven, if not constrained, by data availability considerations.

${ }^{37}$ Ardagna, Caselli, and Lane (2004) test for the existence of a structural break in the relation between fiscal variables and bond yields for EMU countries due to the inception of the monetary
} 
simple and basic framework to analyze the relation between fiscal variables and bond yields. We have explored a number of different specifications, but decided to concentrate here on one similar to that used in section 5 in order to be consistent throughout the paper.

Thus our basic specification reads

$$
\begin{aligned}
& \text { ras }^{i}=\beta_{0}+\beta_{1} \text { trend }+\beta_{2} * \text { int } 3 m+\beta_{3} * \text { infl }+\beta_{4} *\left[\frac{\text { surplus }}{g d p}\right]^{i}+ \\
&+\beta_{5} *\left[\frac{d e b t}{g d p}\right]^{i}++\beta_{6} *\left[\frac{\text { surplus }}{g d p}\right]^{e m u-i}+\beta_{7} *\left[\frac{d e b t}{g d p}\right]^{\text {emu-i }} .
\end{aligned}
$$

On the left hand side we have the 10 year relative asset swap with respect to Switzerland. In choosing this as the dependent variable we have followed Codogno, Favero, and Missale (2003): this cleans bond yields from exchange rate risk and therefore allows one to pool together data coming before and after the introduction of the euro. Investigating the presence of financial spillovers among EMU member countries, we are forced to look for a reference country that is not part of the monetary union: we have opted for Switzerland as it is small enough not to exert particular influences on European-wide government bond markets and its historical record is one of remarkable stability and sound fiscal position (the return on Swiss bonds is always lower than that paid on other European securities). In addition, Switzerland has not experience any significant change in its budgetary position (contrary for instance to the US, which would represent another natural point of reference) and this is another reason that makes it an excellent benchmark country. Moreover, we can feel sufficiently safe in assuming that the fiscal position of any EMU member state will not influence the yield on Swiss bond as the traditional neutrality of the latter country results in looser linkages with neighboring nations.

The list of controls included in equation 8 comprises the 3 month interest rate, inflation, domestic and foreign primary surplus ${ }^{38}$ and debt to GDP ratios. The superscript $i$ stands for the countries object of our study, namely France, Germany, Italy and the Netherlands, while the label $E M U-i$ indicates the aggregated fiscal position of the other 11 EMU member countries. We have chosen to aggregate foreign fiscal variables in order to avoid potential collinearity problems ${ }^{39}$. All variables as measured as deviation from the relevant Swiss variable. Data are taken from the OECD Economic Outlook except for swap rates which come from Datastream; the availability of this latter variable constitutes the main constraint on the analysis as for most countries swap rates are only reported starting in the early nineties. Given

union. They do not find any support for the hypothesis that the relative importance of national versus world fiscal policy variables have changed as a result to the new monetary regime.

${ }^{38}$ We have chosen not to use the indicator of discretionary fiscal stance à la Blanchard (1990) because the first stage fit needed to compute the sensitivity of the primary balance to GDP growth is extremely poor and therefore our estimates very imprecise.

${ }^{39} \mathrm{~A}$ previous version of the paper used disaggregated variables for the four relevant countries. Results were dominated by noise regardless of whether we used the primary balance or the measure of the fiscal stance proposed by Blanchard (1990). 
that available fiscal indicators are at quarterly frequency, we are left with less than 60 observations (actually between 51 and 56$)^{40}$.

All variables (apart from the 3 month interest rate) display a unit root, so we cannot simply proceed with estimation of the SUR in levels. We first tackle the problem by differencing all nonstationary variables: table 15 reports the results for such specification. Unfortunately none of the control is significant, nor does the inclusion of the squares of the fiscal variables help to improve the situation much. In table 16 we present the results for a specification in which the foreign fiscal variables are interacted with a dummy for EMU. In this way we can directly test the hypothesis that with the introduction of the single currency the fiscal position of other EMU member countries has gained importance. Yet, the last two rows of the table show that the relevant coefficients are significant in some cases (above all Italy), though the surplus coefficients display the wrong sign (so that a larger primary balance would result in a higher interest rate).

Alternatively, we test the hypothesis that equation 8 represent a long-run equilibrium relation and therefore test I(1) variables for cointegration. Residual-based tests on the 4 equations of the SUR give conflicting results: it is possible to reject the null of unit root (equivalent to no cointegration) for residuals of the equation for Italy, France and the Netherlands at 5, 10 and 12.5\% respectively, while this hypothesis cannot be rejected in the case of Germany. Nontheless we have decided to keep the 4 equations together and estimate the whole SUR by DGLS. Results are reported in table 17: many coefficients are now significantly different from zero, but signs often change when we move from one equation (country) to another and it is frankely difficult to tell a clear pattern in the results.

The fact that every country reacts differently to changes in its own fiscal position and in that of other countries may be read as a clue that financial markets can efficiently discriminate among different borrowers. Thus each country faces a cost of borrowing that depends on the status it enjoys on financial markets and on other characteristics of its economic system.

In order to test for the absorption effect mentioned by Kenen (1995) we shift out attention to bond issues rather than primary balance to GDP ratios. Stock variables continue to appear in our analysis as they proxy for market depth and hence for liquidity.

In what follows we restrict our attention to Italy and Germany as their Central Banks publish monthly series for the amount of securities issued by the central government and their total outstanding stock. Data are taken from the statistical annexes of the monthly publications of the Banca d'Italia and the Bundesbank. The estimating equation is not very different from the previous one, although it is now refined and adapted to the new dataset:

\footnotetext{
${ }^{40}$ In a previous version of the paper we had interpolated the series and transformed them to monthly. Results were very poor and we therefore decided to abandon that route.
} 


$$
\begin{aligned}
& \Delta r a s_{t}^{i}=\alpha_{0}+\alpha_{1} t+\alpha_{2} \Delta r a s_{t-1}^{i}+\alpha_{3}\left[\frac{i s s u e}{G D P}\right]_{t}^{i}+\alpha_{4} \Delta\left[\frac{d e b t}{G D P}\right]_{t}^{i}+ \\
& \alpha_{5}\left[\frac{i s s u e}{G D P}\right]_{t}^{j}+\alpha_{6} \Delta\left[\frac{d e b t}{G D P}\right]_{t}^{j} .
\end{aligned}
$$

We continue to use the RAS with respect to Switzerland as our dependent variable in order to be able to clean our data from exchange rate risk and thus maximize the length of the dataset. Superscripts $i$ and $j$ represent Italy or Germany: now we have a bidimensional system, which we again estimate by means of a SUR. Despite the fact that we have to focus on only two countries, we believe that they represent a significant sample in our search for financial spillovers. Germany is the leading economy in the euro area and its securities have long served as benchmark in the bond market; Italy, on the other hand is both a large country (with respect to EMU), is characterized by a very large stock of debt and is traditionally viewed as a "non virtuous' country. The RAS and the total stock of debt to GDP are nonstationary and therefore enter equation 9 in first differences. The regression is run using both 3 and 10 year securities in order to see whether different maturities display different behaviors.

Table 18 reports results for estimation of equation 9 : coefficients on bond issues and stocks are barely significant, so that once again we do not find much support for the idea that by absorbing a larger share of European savings each government can rise the overall cost of borrowing. The signs of the coefficients suggest that while Germany may suffer a limited degree of spillover stemming from the Italian issuing activity, the opposite does not hold. On the contrary, an increase in the stock of Italian debt has a negative impact on both the Italian and the German yield, signaling the presence of liquidity effects. Yet, the fact that for Germany the coefficients of foreign variables are significant while those on domestic ones are not, suggests some caution in the interpretation of these results. The finding that only Italian variables appear to matter (albeit marginally) lends credit to the view that financial markets are indeed able to discriminate among different issuers so that the same action taken by different actors have dissimilar results depending on the identity of the debtor. Hence the privileged status enjoyed by German securities would grant less stringent limits to the public finances of the Bundesrepublik, while the fact that Italy has one of the world largest public debt implies closer surveillance by market participants. This is reminiscent of the results by Flandreau, Le Cacheaux, and Zumer (1998) according to whom financial markets behave in nonlinear ways and only beyond a given threshold do borrowers start feeling the bite of market discipline.

To explore this intuition in more detail we have added the squares of bond issues and debt stocks to the estiating equation, but the picture does not change. Also, we have interacted them with a dummy for EMU, but again these new controls are not significant. Another attempt to improve the fit of the equation (and the results) consists of augmenting equation 9 along the line of Afonso and Strauch (2004). Table 19 shows the outcome of the empirical analysis when we include among the regressors 
the slope of the yield curve and a measure of stock market volatility. The former, which is measured by the difference between the yield on 10 year government bonds and the 3 month Euribor, captures future growth expectations: a steeper slope reduces the risk of private relative to government securities, and therefore pushes up the cost of borrowing for the government. On the contrary, the standard deviation of daily return on the S\&P500 index proxies for stock market risk and is supposed to reduce the return required by investors. The table highlights that such modifications do not produce any improvement in the results and gives us some confidence in the fact that our (negative) findings are not driven by the particular specification chosen for the analysis.

\section{Conclusion}

The paper has investigated the presence of negative financial spillovers among euro area government bond yields and their relations with fiscal imbalances. While returns on assets issued by different European governments do show a large degree of comovements, little evidence emerges to relate this common dynamics to the fiscal positions of EMU members.

The paper reviews a number of open economy models, focusing in particular on the predictions about the effect of a fiscal expansion on the international rate of interest. Theory does not provide clear cut indications: not only different models give different outcomes, but even modifying a single assumption can lead the same model to reverse its predictions. Hence the issue of fiscal spillovers remains an empirical question.

Evidence from two major historical episodes does not offer much credit to the spillover hypothesis. We have analyzed the impact of German unification and the Italian fiscal crisis of the early nineties on European interest rates. The former in particular represents a large shift in the fiscal and external position of the leading European economy. We therefore expect this to result in a sensible movement in the cost of borrowing faced by other countries as capital started flowing into Germany to finance unification. Moreover, uncover interest parity suggests that in presence of a pegged but adjustable exchange rate, spillover effects should be magnified by depreciation expectations. Contrary to predictions though, evidence offers little support to the spillover hypothesis and shows that in both instances the fiscal deterioration affected only domestic interest rates.

The negative financial spillover hypothesis takes for granted that a relation exists, linking domestic fiscal variables and interest rates. To gather some evidence on the topic we have investigated whether the fiscal position of the euro area as a whole has any impact on the average yield on European government bonds. Econometric analysis does not highlight any significant relation between the fiscal stance and the interest rate and therefore adds to the number of studies that postulates the neutrality of fiscal variables with respect to the cost of borrowing.

In the last part of the paper we have directly examined the behavior of bonds issued by (some) EMU member governments. We have used a number of different 
specifications and considered both fiscal variables and bond issues in order to directly test the absorption hypothesis. Results are less clear cut but overall it appears that neither fiscal imbalances, nor issuance activities have the direct negative impact on interest rates postulated in the SGP.

More work remains to be done in order to understand the role played by factors other than the fiscal variables in determining the strong comovements displayed by European bond yields. In particular, it would be interesting to incorporate more sophisticated measures of liquidity in the picture and check whether this can explain at least part of the phenomenon.

\section{References}

Afonso, A., And R. Strauch (2004): "Fiscal policy events and interest rate swap spreads: evidence from the EU," Working Paper 303, European Central Bank.

Aoki, M., And A. LeiJonhufvud (1987): "The stock-flow analysis of investment," Working Paper 445, UCLA.

Ardagna, S., F. Caselli, and T. Lane (2004): "Fiscal discipline and the cost of public debt service: some estimates for OECD countries," Working Paper 10788, NBER.

Artis, M., And B. Winkler (1999): "The stability pact: trading off flexibility for credibility?," in Fiscal Aspects of European Monetary Integration, ed. by M. Huges Hallett, M. Hutchinson, and S. Hougaard Jensen, pp. 157-88. Cambridge University Press.

Baele, L., A. Ferrando, P. Hördahl, E. Krylova, and C. Monnet (2004): "Measuring financial integration in the euro area," Occasional Paper 14, ECB.

Barro, R. (1989): "The neoclassical approach to fiscal policy," in Modern Business Cycle Theory, ed. by R. Barro, vol. Modern Business Cycle Theory, pp. 178-235. Harvard University Press.

Bayoumi, T., M. Goldstein, and G. Woglom (1993): "Do credit markets discipline sovereign borrowers? evidence from U.S. states," Journal of Money Credit and Banking, 27(4), 1045-59.

Bernoth, K., J. von Hagen, and L. Schuknecht (2004): "Sovereign Risk Premia in the European Bond Market," Discussion Paper 4465, CEPR. 
Blanchard, O. (1985): "Debt, deficits and finite horizons," Journal of Political Economy, 93(2), 223-47.

(1990): "Suggestions for a new set of fiscal indicators," Working Paper 79, OECD Economics Department.

Branson, W. (1988): "International adjustment and the dollar: policy illusions and economic constraints," in Economic Policy Coordination, ed. by W. Guth, pp. 44-84. IMF.

Breedon, F., B. Henry, and G. Williams (1999): "Long-term interest rates: evidence on the global capital market," Oxford Review of Economic Policy, 15(2), $128-42$.

Brunila, A., J. Hukkinen, and M. Tujula (1999): "Indicators of the cyclically adjusted budget balance: the Bank of Finland's experience," Discussion Paper 1, Bank of Finland.

Buiter, W., G. Corsetti, and N. Roubini (1993): "Disavanzo eccessivo, ragionevolezza e nonsense nel Trattato di Maastricht," Rivista di Politica Economica, VI, 3-82.

Bundesbank (1997): "Trends in public sector debt since German unification," Deutsche Bundesbank Monthly Report, March, 17-31.

Camarero, M., J. Ordoñez, and C. Tamarit (2003): "Tests for interest rate convergence and structural break in the EMS: further analysis," Applied Financial Economics, 12, 447-56.

Cheung, S. (1996): "Provincial credit ratings in Canada: an ordered probit analysis," Working Paper 96-6, Bank of Canada.

Chinn, M., and J. Frankel (2003): "The euro area and world interest rates," Working Paper 0317, Santa Cruz Center for International Economics.

Codogno, L., C. Favero, and A. Missale (2003): "Governement bond spreads," Economic Policy, 18(37), 503-32.

Corsetti, G., And P. Pesenti (2001): "Welfare and macroeconomic interdependence," Quarterly Journal of Economics, 116(2), 421-45.

Cottarelli, C., and M. Mecagni (1991): "The risk premium over Italian government debt, 1976-88," in Macroeconomics and Macroeconomic Policy Issues, ed. by T. Mayer, and F. Spinelli, vol. 11/91 of Quaderni di Economia e Banca, pp. 33-72. Banca di Trento e Bolzano.

Diamond, P. (1965): "National debt in a neoclassic growth model," American Economic Review, 55, 1126-50. 
Dornbusch, R., And H. Wolf (1992): "Economic transition in Eastern Germany," Brookin Papers on Economic Activity, 1, 235-72.

Dunne, P., M. Moore, and R. Portes (2003): "Defining benchmark status: an application using euro-area bonds," Working Paper 9087, NBER, mimeo.

Eichengreen, B., And C. Wyplosz (1993): "The unstable EMS," Brookin Papers on Economic Activity, 1, 51-143.

FARina, F., And R. TAmborini (2002): "Le politiche di stabilizzazione in Europa nel nuovo regime di unione monetaria," in Da Nazioni a Regioni. Mutamenti Strutturali e Istituzionali dopo l'Ingresso nella Unione Monetaria Europea, ed. by F. Farina, and R. Tamborini. Il Mulino.

Favero, C. (2001): Applied Macroeconometrics. Oxford University Press.

Flandreau, M., J. Le Cacheaux, and F. Zumer (1998): "Stability without a pact? Lessons form the European gold standard, 1880-1914," Economic Policy, $13(26), 115-62$.

Fleming, M. (1962): "Domestic financial policies under fixed and under floating exchange rates," IMF Staff Papers, 9, 369-79.

Flood, R., And P. Garber (1984): "Collapsing exchange rate regimes: some linear examples," Journal of International Economics, 17, 1-13.

Ford, R., AND D. LAXTON (1999): "World public debt and real interest rates," Oxford Review of Economic Policy, 15(2), 77-94.

Frenkel, J., And A. Razin (1992): Fiscal Policies and the World Economy. The MIT Press, Cambridge, 2nd edn.

Gale, W., and P. Orszag (2003): "The Economic Effects of Long-Term Fiscal Discipline," Discussion Paper 8, Urban-Brookings Tax Policy Center.

Giavazzi, F., And M. Pagano (1988): "The advantage of tying one's hands: EMS discipline and central bank credibility," European Economic Review, 32, 1055-82.

Gravelle, T. (1999): "Liquidity of the government of Canada securities market: stylized facts and some market microstructure comparisons to the United States treasury market," Working Paper 11, Bank of Canada.

Hartman, P., A. Maddaloni, and S. Manganelli (2003): "The euro area financial system: structure, integration and policy initiatives," Working Paper 230, European Central Bank.

Kenen, P. (1995): Economic and Monetary Union in Europe. Cambridge University Press. 
Kormendi, R., and A. Protopapadakis (2004): "Budget deficits, current account deficits and interest rates: the systematic evidence on Ricardian equivalence," mimeo.

Krugman, P. (1979): "A model of balance of payments crises," Journal of Money Credit and Banking, 11, 311-25.

LAmfalussy, A. (1989): "Macro-coordination of fiscal policies in an economic and monetary union in Europe," in Report on Economic and Monetary Union in the European Community, ed. by Committee for the Study of Economic and Monetary Union, pp. 91-125. Office for the Official Publications of the European Communities.

LAUBACH, T. (2003): "New evidence on the interest rate effects of budget deficits and debt," Finance and Economics Discussion Series 12, Board of Governors of the Federal Reserve System.

Leijonhufvud, A. (1973): "Effective demand failures," Swedish Economic Journal, 75(1), 27-48.

Leith, C., And S. Wren-Lewis (2001): "Compatability Between Monetary and Fiscal Policy Under EMU," Discussion Paper in Economics 01-15, University of Glasgow.

Lemmen, J., and C. Goodhart (1999): "Credit risk and European government bond markets: a panel data econometric analysis," Eastern Economic Journal, 25(1), $77-107$.

LøNNING, I. (2000): "Default premia on European government debt," Weltwirtschaftliches Archiv, 136(2), 259-83.

Mundell, R. (1963): "Capital mobility and stabilization policy under fixed and flexible exchange rates," Canadian Journal of Economics and Political Science, $29,475-85$.

(1964): "A reply: capital mobility and size," Canadian Journal of Economics and Political Science, 30, 421-31.

OBstFeld, M. (1996): "Models of currency crises with self-fulfilling features," Journal of International Money and Finance, 15, 141-7.

Obstfeld, M., And K. Rogoff (1996): Foundations of international macroeconomics. The MIT Press.

Perée, E., And A. Steinherr (2001): "The euro and capital markets: a new era," World Economy, 24(10), 1295-1308.

Piga, G., And G. Valente (2004): "The term structure of interest rates and the public debt issuance policy: a note," Finance Letters, 2(2). 
Restoy, F. (1996): "Interest rates and fiscal discipline in monetary unions," European Economic Review, 40(8), 1629-46.

Rose, A., And L. Svensson (1994): "European exchange rate credibility before the fall," European Economic Review, 38, 1185-216.

SEATER, J. (1993): "Ricardian equivalence," Journal of Economic Literature, 31, $142-90$.

SinN, H.-W. (1996): "International implication of German unification," Working Paper 5839, NBER.

Stock, J., And M. WATson (1993): "A simple estimator of cointegrating vectors in hiher order integrated systems," Econometrica, 61(4), 783-820.

TAMborini, R. (1997): "Living in the EMU. The dynamics of the Maastricht Treaty's fiscal rules," Rivista Italiana degli Economisti, II(3), 335-59.

(2002): "One monetary giant with many fiscal dwarfs: the efficiency of macroeconomic stabilitzation policies in the EMU," Discussion paper 4.02, Dipartimento di economia, Università di Trento.

Thygesen, N. (1999): "Fiscal institutions in EMU and the stability pact," in Fiscal Aspects of European Monetary Integration, ed. by A. Huges Hallett, M. Hutchinson, and S. Hougaard Jensen, pp. 15-36. Cambridge University Press. 


\section{Tables}

Table 1: German fiscal position: summary statistics

\begin{tabular}{rrrrr} 
& \multicolumn{4}{c}{ Period averages } \\
\cline { 2 - 5 } & $\begin{array}{c}\text { debt } \\
\text { growth rate }\end{array}$ & deficit & $\begin{array}{r}\text { current } \\
\text { account }\end{array}$ & $\begin{array}{r}\text { financial } \\
\text { account }\end{array}$ \\
\hline \hline 1985 to 1989 & $5.88 \%$ & 19.66 & 40.16 & -41.73 \\
1986 to 1990 & $8.46 \%$ & 23.56 & 46.08 & -48.97 \\
1989 to 1994 & $15.07 \%$ & 59.77 & -7.92 & 9.46 \\
1991 to 1995 & $16.57 \%$ & 64.23 & -22.25 & 29.19 \\
\hline \hline
\end{tabular}

Data in billion DM. Source: IMF IFS.

Table 2: Impact of German unification on European-wide variables

\begin{tabular}{ccc} 
& deficit $_{G e r} /$ debt $_{E U^{\dagger}}$ & deficit $_{G e r} / G D P_{E U^{\ddagger}}$ \\
\hline \hline 1989 & $0.35 \%$ & $0.05 \%$ \\
1990 & $4.03 \%$ & $0.47 \%$ \\
1991 & $4.22 \%$ & $0.67 \%$ \\
1992 & $4.05 \%$ & $0.76 \%$ \\
1993 & $3.68 \%$ & $0.84 \%$ \\
1994 & $2.03 \%$ & $0.46 \%$ \\
1995 & $2.47 \%$ & $0.62 \%$
\end{tabular}

notional limits implied by Maastricht criteria

$\frac{1.00 \%}{1.00 \%}$
$\ddagger$ EMU 11 
Table 3: Yield on German and European bonds

\begin{tabular}{llrrrrrrr} 
& & \multicolumn{7}{c}{ Months before and after unification } \\
\cline { 3 - 9 } & & \multicolumn{1}{c}{3} & \multicolumn{1}{c}{6} & \multicolumn{1}{c}{12} & \multicolumn{1}{c}{18} & \multicolumn{1}{c}{24} & 36 \\
\hline \hline Germany & before & 8.96 & 8.73 & 7.60 & 6.90 & 6.35 & 6.21 & 5.60 \\
& after & 8.64 & 9.21 & 8.95 & 8.50 & 8.51 & 8.28 & 6.62 \\
& & & & & & & & \\
Europe $^{\dagger}$ : GDP weighted & before & 11.18 & 11.35 & 10.53 & 9.98 & 9.44 & 9.38 & 9.47 \\
& after & 10.96 & 11.47 & 11.07 & 10.71 & 10.37 & 10.22 & 8.77 \\
Europe $^{\dagger}$ : trade weighted & before & 10.67 & 10.82 & 10.01 & 9.37 & 8.83 & 8.82 & 8.86 \\
& after & 10.46 & 10.99 & 10.61 & 10.23 & 9.96 & 9.79 & 8.25 \\
\hline \hline
\end{tabular}

$\dagger$ Austria, Belgium, Denmark, France, Ireland, Italy, Luxembourg, Netherlands, Portugal, Spain, Sweden, UK. 
Table 4: Spread vis-à-vis German yield

\begin{tabular}{|c|c|c|c|c|c|c|c|c|}
\hline & & \multicolumn{7}{|c|}{ Months before and after unification } \\
\hline & & 1 & 3 & 6 & 12 & 18 & 24 & 36 \\
\hline \multirow[t]{2}{*}{ Austria } & before & -0.15 & 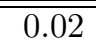 & 0.25 & 0.27 & 0.18 & 0.41 & 1.02 \\
\hline & after & 0.07 & -0.23 & -0.15 & 0.03 & 0.14 & 0.32 & 0.28 \\
\hline \multirow[t]{2}{*}{ Belgium } & before & 0.89 & 1.18 & 2.07 & 1.50 & 1.70 & 1.63 & 2.22 \\
\hline & after & 0.96 & 1.34 & 1.03 & 0.87 & 0.51 & 0.62 & 0.37 \\
\hline \multirow[t]{2}{*}{ France } & before & 0.66 & 1.24 & 1.54 & 1.79 & 2.27 & 2.73 & 3.72 \\
\hline & after & 0.97 & 1.31 & 0.98 & 0.65 & 0.28 & 0.46 & 0.50 \\
\hline \multirow[t]{2}{*}{ Ireland } & before & 0.98 & 1.70 & 1.68 & 2.06 & 2.06 & 3.40 & 5.33 \\
\hline & after & 0.88 & 1.35 & 0.94 & 0.74 & 0.34 & 0.59 & 0.87 \\
\hline \multirow[t]{2}{*}{ Italy } & before & 2.57 & 2.82 & 3.84 & 3.94 & 3.67 & 3.91 & 3.89 \\
\hline & after & 2.69 & 2.22 & 2.86 & 4.59 & 4.45 & 4.83 & 5.26 \\
\hline \multirow[t]{2}{*}{ Luxembourg } & before & -0.45 & -0.24 & 0.74 & 0.38 & -0.21 & 0.23 & 2.54 \\
\hline & after & -0.22 & -0.64 & -0.42 & -0.28 & -0.41 & -0.36 & 0.37 \\
\hline \multirow[t]{2}{*}{ Netherlands } & before & -0.01 & 0.25 & 0.15 & 0.30 & 0.15 & 0.31 & 0.68 \\
\hline & after & 0.10 & -0.05 & 0.11 & 0.14 & 0.21 & 0.02 & -0.03 \\
\hline \multirow[t]{2}{*}{ Portugal } & before & 9.51 & 9.65 & 10.23 & 8.27 & 7.60 & 7.53 & 9.64 \\
\hline & after & 9.90 & 9.65 & 9.83 & 9.87 & 8.62 & 6.82 & 7.90 \\
\hline \multirow[t]{2}{*}{ Spain } & before & 5.67 & 6.13 & 6.89 & 6.88 & 6.47 & 4.65 & 7.60 \\
\hline & after & 5.81 & 5.93 & 5.59 & 3.42 & 3.36 & 3.42 & 3.72 \\
\hline \multirow[t]{2}{*}{ Switzerland } & before & -2.64 & -2.15 & -1.85 & -1.78 & -2.12 & -2.07 & -1.49 \\
\hline & after & -2.56 & -2.67 & -2.27 & -2.52 & -2.16 & -1.30 & -2.08 \\
\hline \multirow[t]{2}{*}{ UK } & before & 2.53 & 2.73 & 2.36 & 2.98 & 3.10 & 3.11 & 3.30 \\
\hline & after & 2.39 & 2.11 & 1.47 & 1.84 & 1.05 & 0.74 & 1.77 \\
\hline
\end{tabular}

Data for Finland not available 
Table 5: Development of Italian public finances

\begin{tabular}{rrrrr} 
& \multicolumn{3}{c}{ Percentage of GDP } \\
\cline { 2 - 5 } & deficit & debt & $\begin{array}{r}\text { primary } \\
\text { balance }\end{array}$ & $\begin{array}{r}\text { interest } \\
\text { payments }\end{array}$ \\
\hline \hline 1970 & $-4.82 \%$ & $34.13 \%$ & $-1.00 \%$ & $0.78 \%$ \\
1971 & $-6.56 \%$ & $38.28 \%$ & $-1.52 \%$ & $0.96 \%$ \\
1972 & $-7.39 \%$ & $42.51 \%$ & $-2.13 \%$ & $1.18 \%$ \\
1973 & $-8.30 \%$ & $43.91 \%$ & $-1.89 \%$ & $1.35 \%$ \\
1974 & $-7.42 \%$ & $43.96 \%$ & $-1.95 \%$ & $1.70 \%$ \\
1975 & $-12.10 \%$ & $49.82 \%$ & $-3.36 \%$ & $2.46 \%$ \\
1976 & $-8.43 \%$ & $48.71 \%$ & $-2.84 \%$ & $2.87 \%$ \\
1977 & $-10.37 \%$ & $51.27 \%$ & $-2.35 \%$ & $3.17 \%$ \\
1978 & $-13.52 \%$ & $57.01 \%$ & $-2.76 \%$ & $3.81 \%$ \\
1979 & $-9.81 \%$ & $56.56 \%$ & $-2.61 \%$ & $3.74 \%$ \\
1980 & $-9.55 \%$ & $54.83 \%$ & $-1.36 \%$ & $4.02 \%$ \\
1981 & $-11.49 \%$ & $57.65 \%$ & $-3.85 \%$ & $4.52 \%$ \\
1982 & $-13.39 \%$ & $62.84 \%$ & $-2.85 \%$ & $6.17 \%$ \\
1983 & $-13.93 \%$ & $68.25 \%$ & $-2.20 \%$ & $7.53 \%$ \\
1984 & $-12.95 \%$ & $71.82 \%$ & $-3.32 \%$ & $8.06 \%$ \\
1985 & $-14.59 \%$ & $78.92 \%$ & $-4.52 \%$ & $8.08 \%$ \\
1986 & $-11.95 \%$ & $83.33 \%$ & $-3.04 \%$ & $8.27 \%$ \\
1987 & $-11.27 \%$ & $87.76 \%$ & $-2.81 \%$ & $7.58 \%$ \\
1988 & $-11.14 \%$ & $90.39 \%$ & $-2.19 \%$ & $8.05 \%$ \\
1989 & $-10.72 \%$ & $93.31 \%$ & $-1.94 \%$ & $8.98 \%$ \\
1990 & $-10.49 \%$ & $95.39 \%$ & $-1.14 \%$ & $9.92 \%$ \\
1991 & $-10.17 \%$ & $98.01 \%$ & $-0.26 \%$ & $11.30 \%$ \\
1992 & $-10.73 \%$ & $105.11 \%$ & $0.95 \%$ & $12.16 \%$ \\
1993 & $-10.09 \%$ & $112.94 \%$ & $1.87 \%$ & $12.59 \%$ \\
\hline \hline Source: IMF IFS and OECD Economic $0 u t l o o k$
\end{tabular}

Table 6: Impact of fiscal variables on real long-term yield: quarterly data

Dependent Variable: real yield on long-term bonds

Method: Least Squares

\begin{tabular}{lccrrrr}
\hline & Coeff & t-Stat & Coeff & t-Stat & Coeff & t-Stat \\
\hline \hline surplus $/ g d p$ & -0.051 & -0.197 & & & -0.229 & -0.394 \\
fiscal $/ g d p$ & & & -0.094 & -0.355 & & \\
debt/gdp & 0.153 & 2.504 & 0.134 & 2.292 & -0.068 & -0.580 \\
(deficit/gdp $)^{2}$ & & & & & & \\
$(\text { debt } / g d p)^{2}$ & & & & & & \\
emu $*$ deficit $/ g d p$ & & & & & 1.136 & 1.777 \\
emu $*$ debt/gdp & & & & & -0.079 & -2.788 \\
\hline
\end{tabular}

$\begin{array}{lrrr}\text { Observations } & 98 & 97 & 98\end{array}$

Constant and time trend not shown

Newey-West HAC Standard Errors 
Table 7: Impact of fiscal variables on real long-term yield: quarterly data

Dependent Variable: real yield on long-term bonds $-1^{s} t$ difference Method: Least Squares

\begin{tabular}{|c|c|c|c|c|c|c|c|c|}
\hline & Coeff & t-Stat & Coeff & t-Stat & Coeff & t-Stat & Coeff & t-Stat \\
\hline$\Delta$ surplus/gdp & 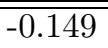 & 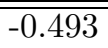 & & & -0.380 & -0.750 & 0.043 & 0.161 \\
\hline$\Delta \mathrm{fiscal} / \mathrm{gdp}$ & & & -0.267 & -0.735 & & & & \\
\hline$\Delta d e b t / g d p$ & -0.203 & -1.431 & -0.208 & -1.551 & -0.268 & -1.342 & -0.016 & -0.109 \\
\hline$\Delta(\text { deficit } / g d p)^{2}$ & & & & & & & 0.647 & 1.157 \\
\hline$\Delta(d e b t / g d p)^{2}$ & & & & & & & -0.186 & -1.324 \\
\hline emu $* \Delta$ deficit $/ g d p$ & & & & & 0.582 & 1.084 & & \\
\hline$e m u * \Delta d e b t / g d p$ & & & & & 0.303 & 1.135 & & \\
\hline Observations & & 97 & & 96 & & 97 & & 97 \\
\hline Adjusted $R^{2}$ & & 0.057 & & 0.066 & & 0.061 & & 0.065 \\
\hline
\end{tabular}

Constant and time trend not shown

Newey-West HAC Standard Errors

Table 8: Impact of fiscal variables on nominal long-term yield: quarterly data

Dependent Variable: nominal yield on long-term bonds $-1^{s} t$ difference

Method: Least Squares

\begin{tabular}{lrrrrrr}
\hline & Coeff & t-Stat & Coeff & t-Stat & Coeff & t-Stat \\
\hline \hline$\Delta$ inflation & 0.461 & 2.607 & 0.440 & 2.544 & 0.461 & 2.723 \\
$\Delta$ surplus $/ g d p$ & -0.119 & -0.368 & -0.407 & -0.784 & 0.079 & 0.270 \\
$\Delta$ debt $/ g d p$ & -0.304 & -2.114 & -0.374 & -1.901 & -0.120 & -0.761 \\
$\Delta(\text { deficit } / g d p)^{2}$ & & & & & 0.690 & 1.235 \\
$\Delta(\text { debt } / g d p)^{2}$ & & & & & -0.178 & -1.287 \\
$e m u * \Delta$ deficit/gdp & & 0.712 & 1.328 & & \\
emu $* \Delta$ debt $/ g d p$ & & 0.323 & 1.194 & & \\
\hline & & & & & \\
Observations & & & 97 & & \\
Adjusted $R^{2}$ & & 0.181 & & 0.195 & & 0.191 \\
\hline \hline
\end{tabular}

Constant and time trend not shown

Newey-West HAC Standard Errors 
Table 9: Impact of fiscal variables on the current account: quarterly data

Dependent Variable: current account to gdp

Method: Least Squares

\begin{tabular}{|c|c|c|c|c|}
\hline & Coeff & t-Stat & Coeff & t-Stat \\
\hline inflation & -0.382 & -7.991 & -0.392 & -8.458 \\
\hline surplus/gdp & -0.213 & -3.090 & & \\
\hline fiscal/gdp & & & 0.230 & 2.972 \\
\hline$d e b t / g d p$ & 0.019 & 0.914 & 0.017 & 0.812 \\
\hline
\end{tabular}

$\begin{array}{lrr}\text { Observations } & 98 & 97\end{array}$

Adjusted $R^{2} \quad 0.645 \quad 0.652$

Constant and time trend not shown

Newey-West HAC Standard Errors

Table 10: Impact of fiscal variables on real 3-year yield

Dependent Variable: real yield on 3 year bonds $-1^{\text {st }}$ difference Method: Least Squares

\begin{tabular}{lrrrr}
\hline & Coeff & t-Stat & Coeff & t-Stat \\
\hline \hline$\left(\right.$ issue $\left.^{g} / g d p\right)$ & 0.039 & 0.817 & 0.018 & 0.375 \\
$\left(\right.$ issue $\left.^{p} / g d p\right)$ & 0.024 & 0.380 & 0.014 & 0.260 \\
$\Delta\left(\right.$ stock $\left.^{g} / g d p\right)$ & -0.041 & -0.671 & -0.024 & -0.480 \\
$\Delta\left(\right.$ stock $\left.^{p} / g d p\right)$ & 0.054 & 1.459 & 0.079 & 2.470 \\
gdp growth & & & 0.051 & 2.779 \\
\hline & & & 63 \\
Observations & & 0.011 & & 0.077 \\
Adjusted $R^{2}$ & & 03 & \\
\hline \hline
\end{tabular}

Constant and time trend not shown

Newey-West HAC Standard Errors

Table 11: Impact of fiscal variables on real 10-year yield

Dependent Variable: real yield on 10 year bonds $-1^{\text {st }}$ difference Method: Least Squares

\begin{tabular}{lrrrr}
\hline & Coeff & t-Stat & Coeff & t-Stat \\
\hline \hline issue $\left.^{g} / g d p\right)$ & 0.059 & 1.161 & 0.048 & 0.912 \\
$\left(\right.$ issue $\left.^{p} / g d p\right)$ & 0.033 & 0.602 & 0.028 & 0.569 \\
$\Delta\left(\right.$ stock $\left.^{g} / g d p\right)$ & -0.038 & -0.588 & -0.028 & -0.476 \\
$\Delta\left(\right.$ stock $\left.^{p} / g d p\right)$ & 0.034 & 0.975 & 0.048 & 1.730 \\
gdp growth & & & 0.029 & 1.379 \\
\hline & & & 63 \\
Observations & & 63 & & 0.029 \\
Adjusted $R^{2}$ & & 0.017 & & \\
\hline \hline
\end{tabular}

Constant and time trend not shown

Newey-West HAC Standard Errors 
Table 12: Impact of fiscal variables on nominal 3-year yield

Dependent Variable: nominal yield on 3 year bonds $-1^{\text {st }}$ difference Method: Least Squares

\begin{tabular}{lrrrr}
\hline & Coeff & t-Stat & Coeff & t-Stat \\
\hline \hline$\Delta$ inflation & 0.129 & 1.257 & 0.153 & 1.631 \\
$\left(\right.$ issue $\left.^{g} / g d p\right)$ & 0.038 & 1.015 & 0.021 & 0.556 \\
$\left(\right.$ issue $\left.^{p} / g d p\right)$ & -0.068 & -1.019 & -0.074 & -1.159 \\
$\Delta\left(\right.$ stock $\left.^{g} / g d p\right)$ & -0.057 & -1.356 & -0.043 & -1.032 \\
$\Delta\left(\right.$ stock $^{p} /$ gdp $)$ & 0.085 & 2.158 & 0.104 & 2.617 \\
gdp growth & & & 0.041 & 2.341 \\
\hline & & & \\
Observations & & 63 & & 63 \\
Adjusted $R^{2}$ & & 0.112 & & 0.191 \\
\hline \hline
\end{tabular}

Constant and time trend not shown

Newey-West HAC Standard Errors

Table 13: Impact of fiscal variables on nominal 10-year yield

Dependent Variable: nominal yield on 10 year bonds $-1^{\text {st }}$ difference Method: Least Squares

\begin{tabular}{lrrrr}
\hline & Coeff & t-Stat & Coeff & t-Stat \\
\hline \hline$\Delta$ inflation & 0.115 & 1.691 & 0.126 & 1.996 \\
$\left(\right.$ issue $^{g} /$ gdp $)$ & 0.058 & 1.817 & 0.050 & 1.593 \\
$\left(\right.$ issue $^{p} /$ gdp $)$ & -0.060 & -1.404 & -0.062 & -1.524 \\
$\Delta\left(\right.$ stock $^{g} /$ gdp $)$ & -0.054 & -1.387 & -0.047 & -1.322 \\
$\Delta\left(\right.$ stock $^{p} /$ gdp $)$ & 0.066 & 2.392 & 0.074 & 2.597 \\
gdp growth & & & 0.019 & 1.567 \\
\hline & & & 63 \\
Observations & & 63 & & 0.125 \\
Adjusted $R^{2}$ & & 0.115 & & \\
\hline \hline
\end{tabular}

Constant and time trend not shown

Newey-West HAC Standard Errors 
Table 14: Impact of fiscal variables on the current account

Dependent Variable: current account to GDP $-1^{\text {st }}$ difference Method: Least Squares

\begin{tabular}{lrrrr}
\hline & Coeff & t-Stat & Coeff & t-Stat \\
\hline \hline issue $/ G D P_{\text {gov }}$ & -0.013 & -0.378 & -0.017 & -0.459 \\
issue $/ G D P_{\text {pvt }}$ & -0.004 & -0.093 & -0.005 & -0.152 \\
$\Delta\left(\right.$ stock $\left./ G D P_{\text {gov }}\right)$ & 0.013 & 0.318 & 0.016 & 0.389 \\
$\Delta\left(\right.$ stock $\left./ G D P_{\text {pvt }}\right)$ & 0.006 & 0.221 & 0.010 & 0.439 \\
GDP growth & & & 0.009 & 0.579 \\
\hline & & & 63 \\
Observations & & 63 & -0.097 \\
Adjusted $R^{2}$ & & -0.083 & & \\
\hline \hline
\end{tabular}

Constant and time trend not shown Newey-West HAC Standard Errors 
Table 15: Impact of domestic and foreign fiscal variables on yields

Dependent Variable: 10 year asset swap relative to Switzerland $-1^{\text {st }}$ difference Method: SUR

\begin{tabular}{|c|c|c|c|c|c|c|c|c|c|}
\hline & \multicolumn{2}{|c|}{ France } & \multicolumn{2}{|c|}{ Germany } & \multicolumn{2}{|c|}{ Italy } & \multicolumn{2}{|c|}{ Netherlands } \\
\hline & & Coeff & t-Stat & Coeff & t-Stat & Coeff & t-Stat & Coeff & t-Stat \\
\hline \multicolumn{2}{|c|}{3 month rate } & -0.034 & -2.57 & -0.024 & -1.332 & -0.006 & -0.329 & -0.047 & -2.33 \\
\hline \multicolumn{2}{|c|}{$\Delta$ inflation } & 0.013 & 0.549 & 0.017 & 1.455 & -0.107 & -1.618 & -0.005 & -0.367 \\
\hline$\Delta$ & ]$_{\text {domestic }}$ & -0.011 & -0.359 & 0.013 & 0.467 & 0.009 & 0.28 & -0.004 & -0.186 \\
\hline$\Delta$ & domestic & -0.012 & -0.382 & 0.01 & 0.609 & -0.009 & -0.434 & -0.004 & -0.319 \\
\hline$\Delta$ & ]$_{\text {foreign }}$ & -0.002 & -0.043 & 0.005 & 0.135 & -0.098 & -1.126 & 0.016 & 0.366 \\
\hline$\Delta$ & $\left.\frac{d e b t}{g d p}\right]_{\text {foreign }}$ & 0.028 & 0.94 & -0.018 & -0.86 & -0.079 & -1.593 & -0.019 & -0.697 \\
\hline \multicolumn{2}{|c|}{ Observations } & & 50 & & 55 & & 53 & & 51 \\
\hline \multicolumn{2}{|c|}{ Adjusted $R^{2}$} & & -0.079 & & -0.115 & & 0.030 & & -0.113 \\
\hline
\end{tabular}

Constant and trend not shown

Table 16: Domestic and foreign fiscal variables \& EMU dummy

Dependent Variable: 10 year asset swap relative to Switzerland - $1^{\text {st }}$ difference Method: SUR

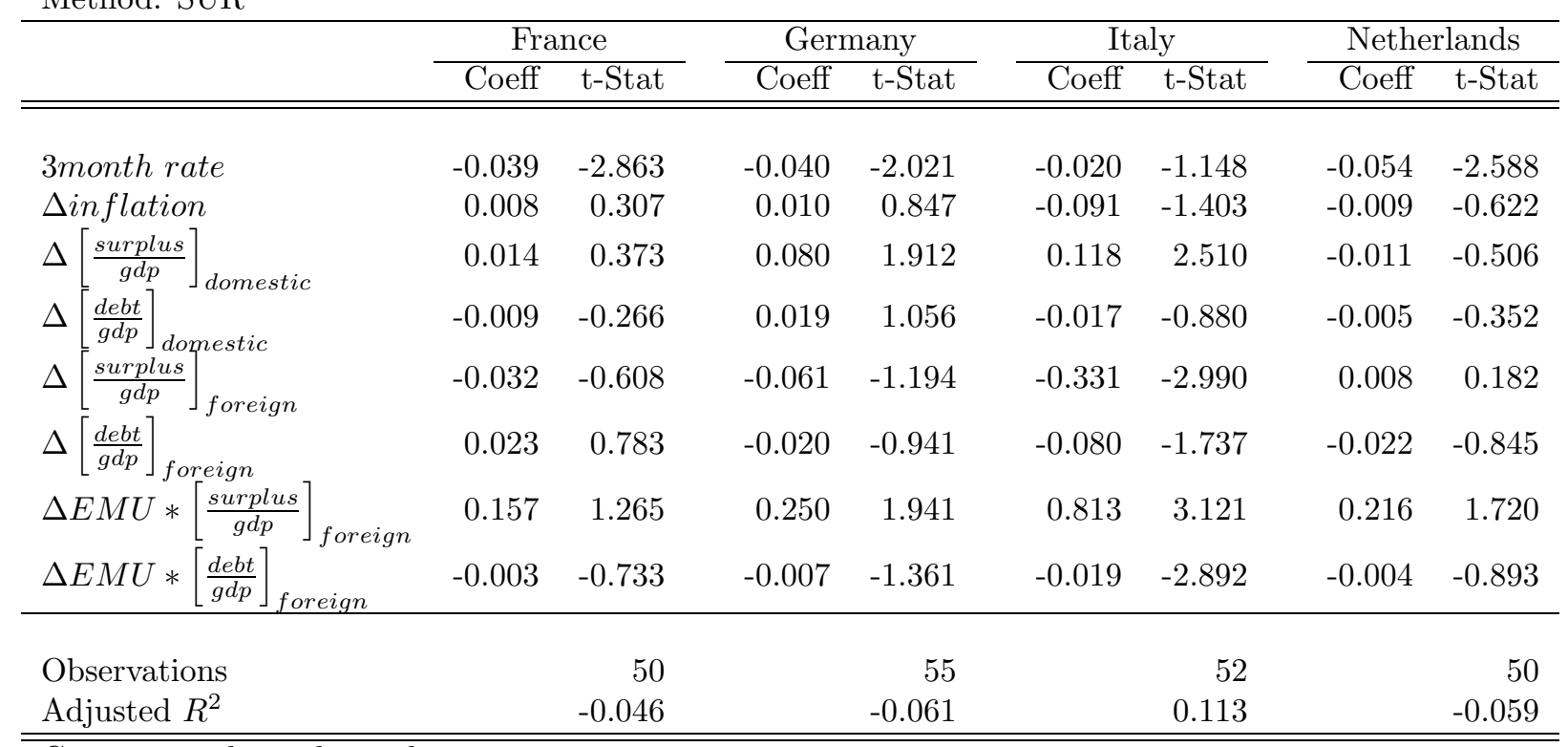

Constant and trend not shown 
Table 17: DGLS estimate of the cointegrating relation

Dependent Variable: 10 year asset swap relative to Switzerland Method: DLGS SUR

\begin{tabular}{|c|c|c|c|c|c|c|c|c|}
\hline & \multicolumn{2}{|c|}{ France } & \multicolumn{2}{|c|}{ Germany } & \multicolumn{2}{|c|}{ Italy } & \multicolumn{2}{|c|}{ Netherlands } \\
\hline & Coeff & t-Stat & Coeff & t-Stat & Coeff & t-Stat & Coeff & t-Stat \\
\hline 3 month rate & -0.051 & -4.702 & -0.077 & -3.206 & 0.011 & 0.430 & -0.121 & -3.532 \\
\hline inflation & 0.044 & 2.284 & -0.098 & -5.208 & 0.038 & 0.479 & -0.096 & -5.325 \\
\hline$\left[\frac{\text { surplus }}{g d p}\right]_{\text {domestic }}$ & 0.037 & 1.046 & -0.138 & -6.283 & 0.111 & 1.410 & -0.145 & -4.140 \\
\hline$\left[\frac{\text { debt }}{g d p}\right]_{\text {domestic }}$ & 0.209 & 5.355 & 0.016 & 1.143 & -0.066 & -3.511 & -0.130 & -8.275 \\
\hline$\left[\frac{\text { surplus }}{g d p}\right]_{\text {foreign }}$ & -0.083 & -1.970 & 0.171 & 7.513 & -0.249 & -1.641 & 0.119 & 3.051 \\
\hline$\left[\frac{d e b t}{g d p}\right]_{\text {foreign }}$ & -0.178 & -4.706 & -0.034 & -3.904 & -0.046 & -3.155 & 0.081 & 6.431 \\
\hline Observations & & 49 & & 52 & & 51 & & 49 \\
\hline Adjusted $R^{2}$ & & 0.759 & & 0.936 & & 0.920 & & 0.815 \\
\hline
\end{tabular}

Constant and trend not shown

Table 18: Impact of bond issues on yields: basic specification

Dependent Variable: 10 and 3 year asset swap relative to Switzerland Method: SUR

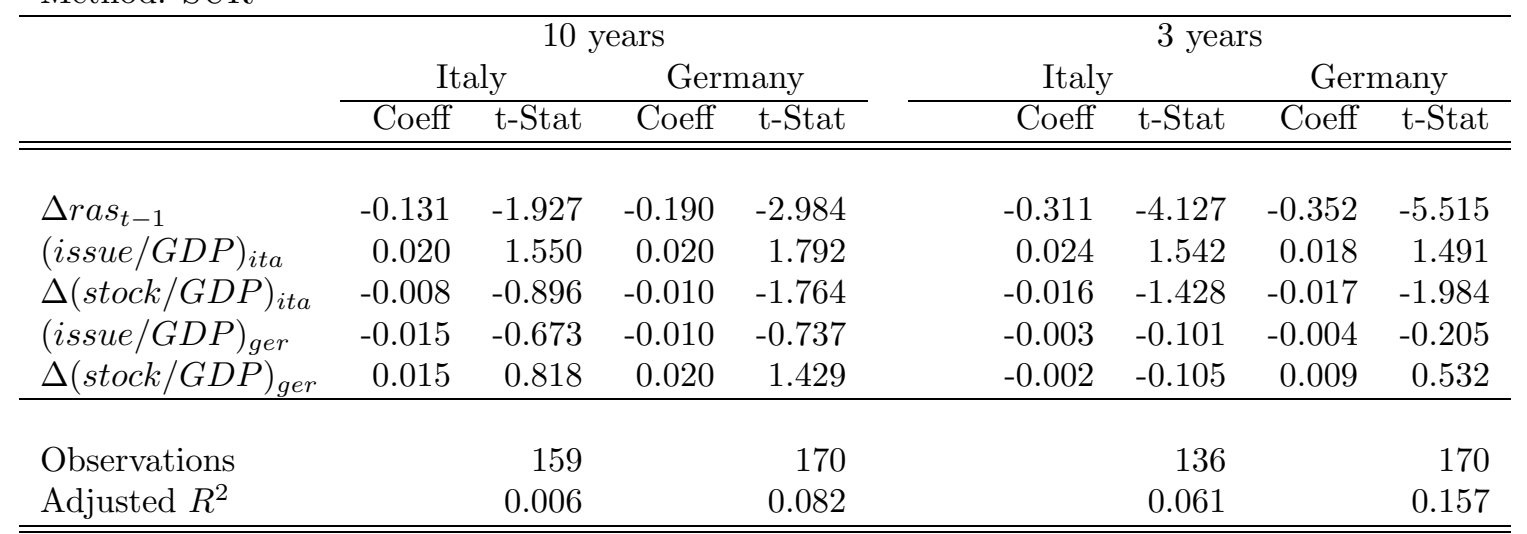

Constant and trend not shown 
Table 19: Impact of bond issues on yields: augmented specification

Dependent Variable: 10 and 3 year asset swap relative to Switzerland Method: SUR

\begin{tabular}{|c|c|c|c|c|c|c|c|c|}
\hline & \multicolumn{4}{|c|}{10 years } & \multicolumn{4}{|c|}{3 years } \\
\hline & \multicolumn{2}{|c|}{ Italy } & \multicolumn{2}{|c|}{ Germany } & \multicolumn{2}{|c|}{ Italy } & \multicolumn{2}{|c|}{ Germany } \\
\hline & Coeff & t-Stat & Coeff & t-Stat & Coeff & t-Stat & Coeff & t-Stat \\
\hline$\Delta \operatorname{ras}_{t-1}$ & -0.14 & -2.063 & -0.184 & -2.937 & -0.314 & -4.139 & -0.354 & -5.556 \\
\hline$\Delta s l p_{t}$ & 0.024 & 0.393 & 0.053 & 1.254 & 0.008 & 0.107 & 0.085 & 1.500 \\
\hline S\&P500volatility & 4.922 & 1.401 & 0.989 & 0.409 & 1.892 & 0.479 & 0.869 & 0.263 \\
\hline$(\text { issue/GDP })_{i t a}$ & 0.02 & 1.584 & 0.016 & 1.751 & 0.024 & 1.516 & 0.017 & 1.405 \\
\hline$\Delta(\text { stock } / G D P)_{i t a}$ & -0.008 & -0.921 & -0.011 & -1.704 & -0.015 & -1.407 & -0.016 & -1.887 \\
\hline$(\text { issue/GDP })_{g e r}$ & -0.015 & -0.671 & -0.01 & -0.637 & -0.002 & -0.074 & -0.002 & -0.085 \\
\hline$\Delta(\text { stock } / G D P)_{\text {ger }}$ & 0.016 & 0.892 & 0.016 & 1.262 & -0.002 & -0.096 & 0.006 & 0.335 \\
\hline Observations & & 159 & & 170 & & 136 & & 170 \\
\hline Adjusted $R^{2}$ & & 0.001 & & 0.079 & & 0.047 & & 0.158 \\
\hline
\end{tabular}

Constant and trend not shown 


\section{Figures}

Figure 1: Current and financial account for Germany: 1971-1998

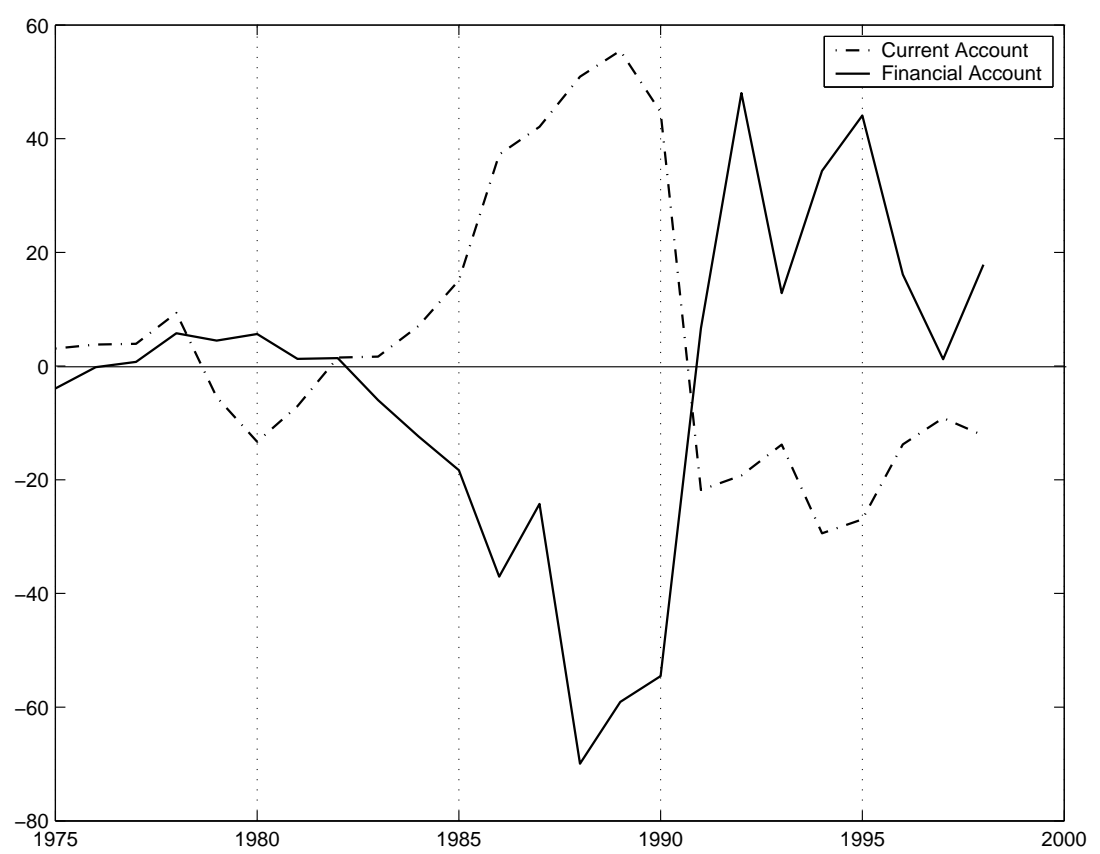

Figures in billion USD. Source: IFS. 
Figure 2: $\mathrm{EU}^{\dagger}$ - Germany long-term interest rate differential

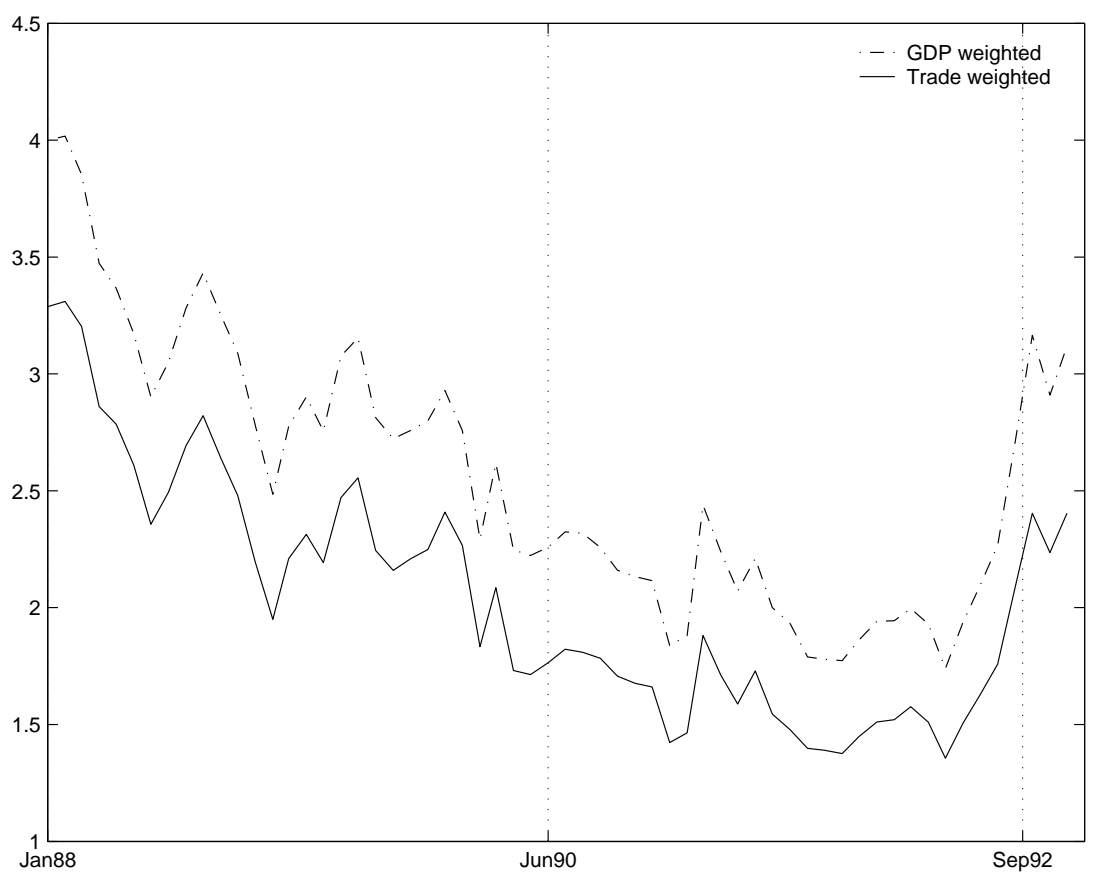

$\dagger$ Austria, Belgium, Denmark, France, Ireland, Italy, Luxembourg, Netherlands, Portugal, Spain, Sweden, UK.

Dot-dashed line represents the difference between the German rate and an average European rate obtained weighting countries' yield by relative GDP shares; solid line repeats the exercise weighting yields by German import shares. 
Figure 3: Change in money stock in Germany, Italy and the UK

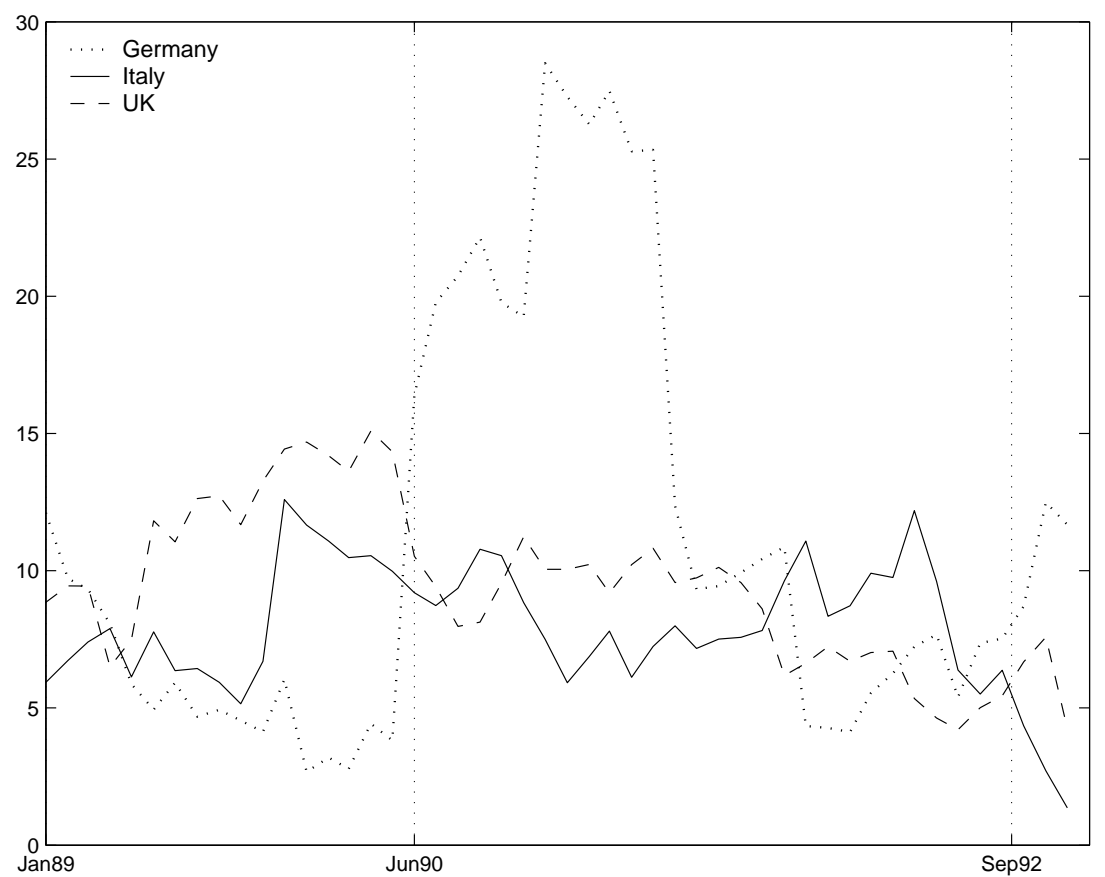

Source: IFS. 
Figure 4: Money market rate in Germany, Italy and the UK

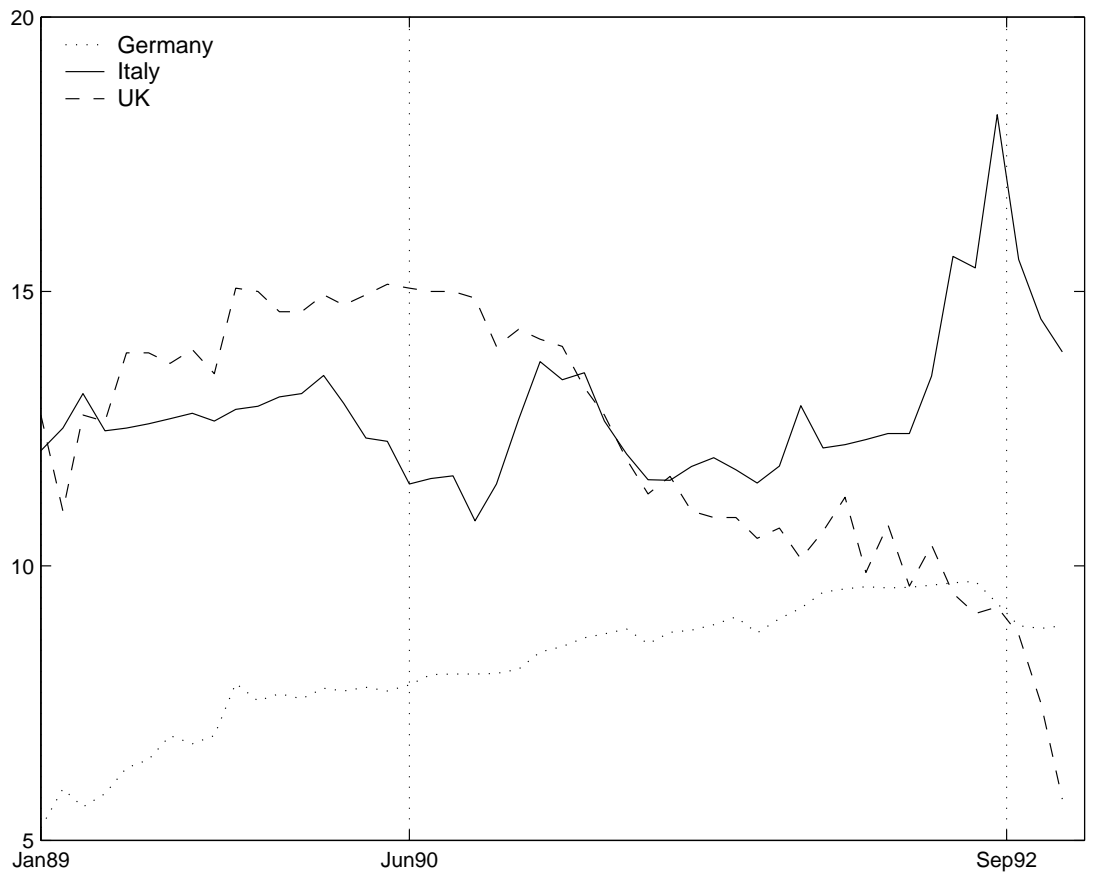

Source: IFS.

Figure 5: Yield on long-term bonds before and after September 1992
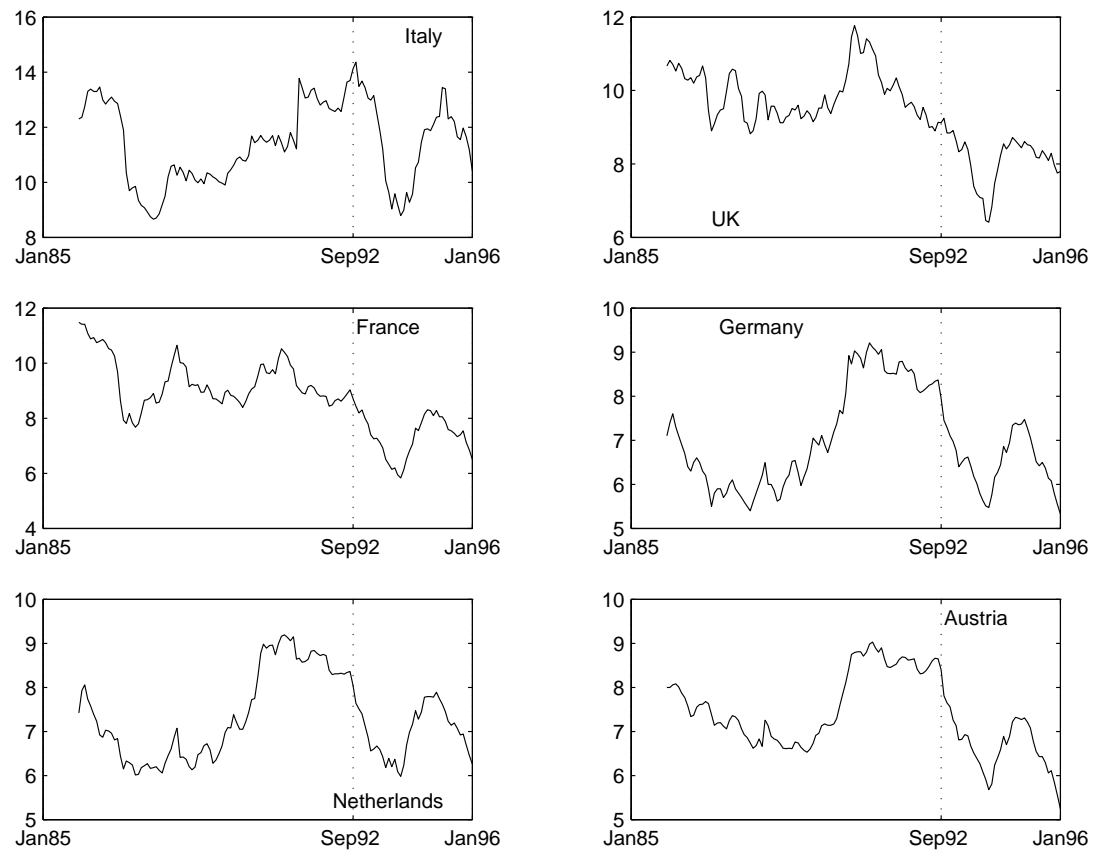
Figure 6: Yield on 10 year government bonds: EMU 11 countries

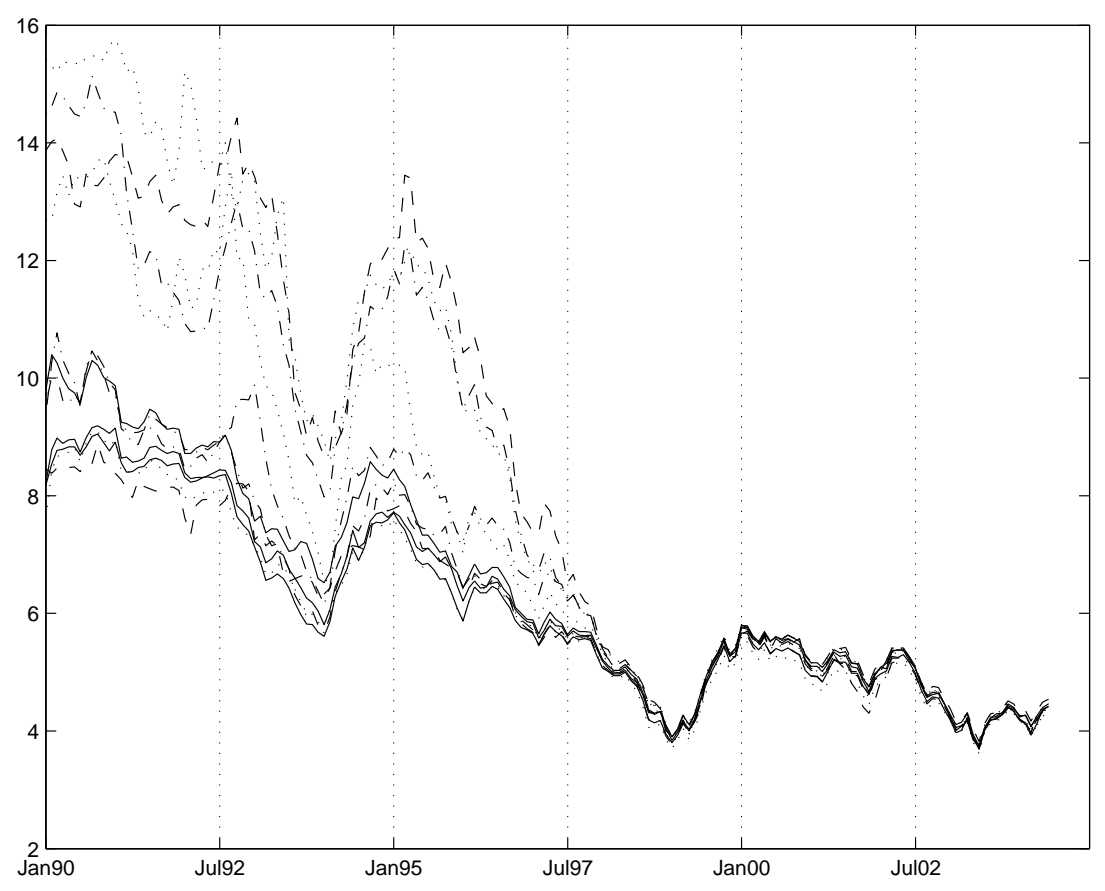


Elenco dei papers del Dipartimento di Economia

2000.1 A two-sector model of the effects of wage compression on unemployment and industry distribution of employment, by Luigi Bonatti

2000.2 From Kuwait to Kosovo: What have we learned? Reflections on globalization and peace, by Roberto Tamborini

2000.3 Metodo e valutazione in economia. Dall'apriorismo a Friedman, by Matteo Motterlini

2000.4 Under tertiarisation and unemployment. by Maurizio Pugno

2001.1 Growth and Monetary Rules in a Model with Competitive Labor Markets, by Luigi Bonatti.

2001.2 Profit Versus Non-Profit Firms in the Service Sector: an Analysis of the Employment and Welfare Implications, by Luigi Bonatti, Carlo Borzaga and Luigi Mittone.

2001.3 Statistical Economic Approach to Mixed Stock-Flows Dynamic Models in Macroeconomics, by Bernardo Maggi and Giuseppe Espa.

2001.4 The monetary transmission mechanism in Italy: The credit channel and a missing ring, by Riccardo Fiorentini and Roberto Tamborini.

2001.5 Vat evasion: an experimental approach, by Luigi Mittone

2001.6 Decomposability and Modularity of Economic Interactions, by Luigi Marengo, Corrado Pasquali and Marco Valente.

2001.7 Unbalanced Growth and Women's Homework, by Maurizio Pugno

2002.1 The Underground Economy and the Underdevelopment Trap, by Maria Rosaria Carillo and Maurizio Pugno. 
2002.2 Interregional Income Redistribution and Convergence in a Model with Perfect Capital Mobility and Unionized Labor Markets, by Luigi Bonatti.

2002.3 Firms' bankruptcy and turnover in a macroeconomy, by Marco Bee, Giuseppe Espa and Roberto Tamborini.

2002.4 One "monetary giant" with many "fiscal dwarfs": the efficiency of macroeconomic stabilization policies in the European Monetary Union, by Roberto Tamborini.

2002.5The Boom that never was? Latin American Loans in London 1822-1825, by Giorgio Fodor.

2002.6L'economia senza banditore di Axel Leijonhufoud: le 'forze oscure del tempo e dell'ignoranza' e la complessità del coordinamento, by Elisabetta De Antoni.

2002.7 Why is Trade between the European Union and the Transition Economies Vertical?, by Hubert Gabrisch and Maria Luigia Segnana.

2003.1 The service paradox and endogenous economic gorwth, by Maurizio Pugno.

2003.2 Mappe di probabilità di sito archeologico: un passo avanti, di Giuseppe Espa, Roberto Benedetti, Anna De Meo e Salvatore Espa.

(Probability maps of archaeological site location: one step beyond, by Giuseppe Espa, Roberto Benedetti, Anna De Meo and Salvatore Espa).

2003.3 The Long Swings in Economic Understianding, by Axel Leijonhufvud.

2003.4 Dinamica strutturale e occupazione nei servizi, di Giulia Felice.

2003.5 The Desirable Organizational Structure for Evolutionary Firms in Static Landscapes, by Nicolás Garrido.

2003.6 The Financial Markets and Wealth Effects on Consumption An Experimental Analysis, by Matteo Ploner. 
2003.7 Essays on Computable Economics, Methodology and the Philosophy of Science, by Kumaraswamy Velupillai.

2003.8 Economics and the Complexity Vision: Chimerical Partners or Elysian Adventurers?, by Kumaraswamy Velupillai.

2003.9 Contratto d'area cooperativo contro il rischio sistemico di produzione in agricoltura, di Luciano Pilati e Vasco Boatto.

2003.10 Il contratto della docenza universitaria. Un problema multitasking, di Roberto Tamborini.

2004.1 Razionalità e motivazioni affettive: nuove idee dalla neurobiologia e psichiatria per la teoria economica? di Maurizio Pugno.

(Rationality and affective motivations: new ideas from neurobiology and psychiatry for economic theory? by Maurizio Pugno.

2004.2 The economic consequences of Mr. G. W. Bush's foreign policy. Can th US afford it? by Roberto Tamborini

2004.3 Fighting Poverty as a Worldwide Goal by Rubens Ricupero

2004.4 Commodity Prices and Debt Sustainability by Christopher L. Gilbert and Alexandra Tabova

2004.5 A Primer on the Tools and Concepts of Computable Economics by K. Vela Velupillai

2004.6 The Unreasonable Ineffectiveness of Mathematics in Economics by Vela K. Velupillai

2004.7 Hicksian Visions and Vignettes on (Non Linear) Trade Cycle Theories by Vela K. Velupillai.

2004.8 Trade, inequality and pro-poor growth: Two perspectives, one message? by Gabriella Berloffa and Maria Luigia Segnana.

2004.9 Worker involvement in entrepreneurial nonprofit organizations. Toward a new assessment of workers? Perceived satisfaction and fairness by Carlo Borzaga and Ermanno Tortia. 
2004.10 A Social Contract Account for CSR as Extended Model of Corporate Governance (Part I): Rational Bargaining and Justification by Lorenzo Sacconi

2004.11 A Social Contract Account for CSR as Extended Model of Corporate Governance (Part II): Compliance, Reputation and Reciprocity by Lorenzo Sacconi

2004.12 A Fuzzy Logic and Default Reasoning Model of Social Norm and Equilibrium Selection in Games under Unforeseen Contingencies by Lorenzo Sacconi and Stefano Moretti

2004.13 The Constitution of the Not-For-Profit Organisation: Reciprocal Conformity to Morality by Gianluca Grimalda and Lorenzo Sacconi

2005.1 The happiness paradox: a formal explanation from psychoeconomics by Maurizio Pugno

2005.2 Euro Bonds: in Search of Financial Spillovers by Stefano Schiavo 
PUBBLICAZIONE REGISTRATA PRESSO IL TRIBUNALE DI TRENTO 